\title{
Effect of PACAP on Hypoxia-Induced Angiogenesis and Epithelial-Mesenchymal Transition in Glioblastoma
}

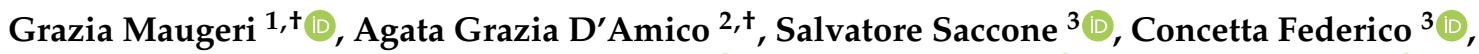 \\ Daniela Maria Rasà ${ }^{1,4}$, Rosario Caltabiano ${ }^{5}\left(\mathbb{D}\right.$, Giuseppe Broggi ${ }^{5}\left(\mathbb{D}\right.$, Salvatore Giunta ${ }^{1}(\mathbb{D}$, \\ Giuseppe Musumeci ${ }^{1}\left(\right.$ ib and Velia $D^{\prime}$ Agata $^{1, *(1)}$
}

1 Department of Biomedical and Biotechnological Sciences, Section of Anatomy, Histology and Movement Sciences, University of Catania, 95100 Catania, Italy; graziamaugeri@unict.it (G.M.); rasa.daniela@gmail.com (D.M.R.); sgiunta@unict.it (S.G.); g.musumeci@unict.it (G.M.)

2 Department of Drug Sciences, University of Catania, 95100 Catania, Italy; agata.damico@unict.it

3 Department of Biological, Geological and Environmental Sciences, Section of Animal Biology, University of Catania, 95123 Catania, Italy; saccosal@unict.it (S.S.); federico@unict.it (C.F.)

4 Department of Neuroscience Rita Levi Montalcini, Neuroscience Institute Cavalieri Ottolenghi, University of Turin, 10124 Turin, Italy

5 Department of Medical and Surgical Sciences and Advanced Technologies "G.F. Ingrassia", Anatomic Pathology, University of Catania, 95123 Catania, Italy; rosario.caltabiano@unict.it (R.C.); giuseppe.broggi@gmail.com (G.B.)

* Correspondence: vdagata@unict.it; Tel.: +39-095-3782147; Fax: +39-095-3782046

+ Co-first authors.

\section{check for} updates

Citation: Maugeri, G.; D'Amico, A.G.; Saccone, S.; Federico, C.; Rasà, D.M.; Caltabiano, R.; Broggi, G.; Giunta, S.; Musumeci, G.; D'Agata, V. Effect of PACAP on Hypoxia-Induced Angiogenesis and

Epithelial-Mesenchymal Transition in Glioblastoma. Biomedicines 2021, 9 , 965. https://doi.org/10.3390/ biomedicines 9080965

Academic Editor: Miguel Idoate

Received: 26 May 2021

Accepted: 3 August 2021

Published: 5 August 2021

Publisher's Note: MDPI stays neutral with regard to jurisdictional claims in published maps and institutional affiliations.

Copyright: (c) 2021 by the authors. Licensee MDPI, Basel, Switzerland. This article is an open access article distributed under the terms and conditions of the Creative Commons Attribution (CC BY) license (https:// creativecommons.org/licenses/by/ $4.0 /)$.
Abstract: Pituitary adenylate cyclase-activating polypeptide (PACAP) exerts different effects in various human cancer. In glioblastoma (GBM), PACAP has been shown to interfere with the hypoxic micro-environment through the modulation of hypoxia-inducible factors via PI3K/AKT and MAPK/ERK pathways inhibition. Considering that hypoxic tumor micro-environment is strictly linked to angiogenesis and Epithelial-Mesenchymal transition (EMT), in the present study, we have investigated the ability of PACAP to regulate these events. Results have demonstrated that PACAP and its related receptor, PAC1R, are expressed in hypoxic area of human GBM colocalizing either in epithelial or mesenchymal cells. By using an in vitro model of GBM cells, we have observed that PACAP interferes with hypoxic/angiogenic pathway by reducing vascular-endothelial growth factor (VEGF) release and inhibiting formation of vessel-like structures in H5V endothelial cells cultured with GBM-conditioned medium. Moreover, PACAP treatment decreased the expression of mesenchymal markers such as vimentin, matrix metalloproteinase 2 (MMP-2) and matrix metalloproteinase 9 (MMP-9) as well as CD44 in GBM cells by affecting their invasiveness. In conclusion, our study provides new insights regarding the multimodal role of PACAP in GBM malignancy.

Keywords: PACAP; glioblastoma; hypoxia; angiogenesis; VEGF; epithelial-mesenchymal transition

\section{Introduction}

Glioblastoma (GBM) is the most common and aggressive primary brain tumor in adults [1]. The majority of GBMs are classified as primary, since they develop de novo, whereas a small minority, known as secondary GBMs, slowly progress from lower grade of astrocytomas [2]. Among tumors, GBM displays strong proliferation index, diffused infiltration, aberrant angiogenesis and poor outcome [3]. Despite the multimodal therapeutic approach, comprising surgery followed by radiotherapy and treatment with the alkylating agent, Temozolomide, the median survival rate of GBM-affected patients is around 2 years after diagnosis [4]. The highly malignant phenotype of this tumor as well as its resistance to chemotherapy and radiotherapy is exacerbated by the extensive hypoxic areas in the tumor bulk [5]. In these regions, low oxygen tension arises from reduced vascular perfusion or insufficient oxygen diffusion as consequence of higher metabolic demand of 
the growing tumor [6]. The early response to hypoxia is mediated by hypoxia-inducible factors (HIFs) composed of an $\alpha$ oxygen-related sub-unit (HIF $\alpha$ ), including HIF- $1 \alpha$, and an aryl hydrocarbon receptor nuclear translocator (ARNT) sub-unit, also known as HIF-1 $\beta$, constitutively expressed into the nucleus independently to the presence of oxygen [7]. Under hypoxia, the HIF- $1 \alpha$ sub-unit escapes to cytoplasmic degradation by ubiquitin proteasome system, and it translocates into the nucleus, forming a heterodimer with the $\beta$-sub-unit. This complex is able to bind hypoxia response elements (HREs), leading to activation of several downstream target genes, including the vascular endothelial growth factor (VEGF), the key player of tumoral angiogenesis [8-14]. Many papers have confirmed the strategic role carried out by HIF- $1 \alpha$ in adaptive response of GBM cells exposed to microenvironmental hypoxia. In fact, HIF- $1 \alpha$ not only contributes to aberrant development of new blood vessels in malignant gliomas, but it is also involved in a variety of tumoral biological processes such as cell metabolism, invasion, survival and proliferation [15-17]. Furthermore, HIF- $1 \alpha$ has been also considered a main factor involved in tumor metastasis by promoting epithelial to mesenchymal transition (EMT) of cancer cells $[18,19]$. EMT is a crucial biological process whereby cancer cells lose epithelial features toward a more aggressive and invasive mesenchymal phenotype. Accordingly, EMT is involved in malignancy of different solid tumors, including GBM [20]. Recent papers have demonstrated that hypoxic micro-environment within GBM recruits circulating or residential myeloid cells (i.e., macrophages or microglia) into tumoral stroma by triggering the activation of the EMT process involved in tumor malignant progression and invasiveness of cancer cells in surrounding normal tissue brain [21,22].

Pituitary adenylate cyclase-activating polypeptide (PACAP) is a neuropeptide belonging to the (VIP)/secretin/glucagon family. Peptide exists into two active forms of 38 (PACAP38) or 27 amino acid residues (PACAP27), and it exerts its actions by activating three different $G$ protein-coupled receptors: the specific PACAP receptor (PAC1R) and VPAC1 and VPAC2 receptors binding either PACAP or VIP with similar affinity [23]. The stimulation of these receptors triggers different signaling cascades mediated by adenylatecyclase (AC) or phospholipase-C (PLC) activation as well as calcium-regulated mechanisms [24]. PACAP and its receptors are expressed in several tissues and organs [25,26]. Many papers have described the physiopathological role of this peptide [27-31]. In particular, it plays a protective role against various insults and in different neurodegenerative diseases [32-39]. Intriguingly, the role of PACAP in cancer is controversial and related to the histopathological hallmarks of the tumor [24,40-43].

The expression of PACAP and its related receptors has been largely demonstrated in human gliomas [44-48]. The database "The Human Protein Atlas" [49] reports a correlation analysis between tumoral ADCYAP1 mRNA expression and patient clinical outcome. In particular, 71 patients had a low gene expression and less survival probability than another 82 patients showing high $A D C Y A P 1$ expression and high survival probability. However, no significant difference was detected between groups. Many papers have investigated the functional role of the peptide in GBM. In particular, some studies showed the proliferative effect of PACAP on mouse C6 glioma cells $[43,50,51]$ in contrast Vertongen et al. [52], who demonstrated the ability of PACAP to reduce T98G human glioma cells proliferation. In accord, some studies performed on two human GBM cell lines demonstrated that PACAP agonists counteract cancer cells migration and invasion by acting through inhibition of AKT signaling pathway $[53,54]$. The overactivation of PI3K/Akt pathway caused an up-regulation of matrix metalloproteinase 2 (MMP-2) and matrix metalloproteinase 9 (MMP-9), which in turn promoted GBM cells migration [55]. Recently, it has been shown that PACAP significantly reduced glioma cells invasion in the rat brain parenchyma [56] by blocking sonic hedgehog-GLI1 (Shh/GLI1) pathway, another signaling cascade implicated in tumor progression [57]. In our previous work, we have demonstrated that PACAP counteracts HIFs expression in GBM cells exposed to DFX-induced hypoxia by acting through PI3K/AKT and MAPK/ERK inhibition [17]. Moreover, the peptide affected the expression levels of VEGF and its receptors in neuroblastoma cells exposed to hypoxia 
mimetic conditions induced by DFX treatment [40]. Considering the central role of HIF- $1 \alpha$ in neo-angiogenesis and EMT event of GBM, we have here evaluated whether PACAP could modulate these events triggered by micro-environmental hypoxia. The ability of PACAP to counteract EMT process has been previously demonstrated in human renal proximal tubule epithelial cells (PTECs) [58]. However, no studies in our knowledge exist regarding the PACAP effect on EMT in cancer, particularly in GBM. In the present paper, we first demonstrated that PACAP and its receptor are expressed either in epithelial or mesenchymal cells of human GBM. Our results have also shown that PACAP decreases the production and release of VEGF in cells exposed to deferoxamine mesylate, a wellknown hypoxia mimetic agent. In particular, it reduced tube formation in H5V endothelial cells cultured with GBM conditioned medium. Furthermore, the peptide interfered with EMT in GMB cells by reducing the expression of mesenchymal markers and affecting their migratory capacity. These data provide new insights regarding the multimodal involvement of PACAP in GBM aggressiveness.

\section{Methods}

\subsection{Human Glioblastoma Samples and Cell Line}

Human glioblastoma frozen sections were provided from Anatomic Pathology of "G.F. Ingrassia" Department after patients signed informed consent. The study was approved by the local ethics committee of the Research Center on Motor Activities (CRAM), University of Catania (Protocol Number: CRAM-015-2020, 16/03/2020). Experiments were also carried on human GBM cell line U87MG (wild-type p53) (ATCCC number \#HTB-14), obtained from the American Type Culture Collection (ATCC, Rockville, MD, USA). Cells were grown in Dulbecco's modified Eagle's medium (DMEM) supplemented with $10 \%$ of heatinactivated fetal bovine serum (FBS), $100 \mathrm{U} / \mathrm{mL}$ penicillin and $100-\mu \mathrm{g} / \mathrm{mL}$ streptomycin (Sigma-Aldrich, Steinheim, Germany). Cells were incubated at $37^{\circ} \mathrm{C}$ in a humidified atmosphere with $5 \% \mathrm{CO}_{2}$, as previously described by Maugeri et al. [59].

\subsection{Treatments}

To mimic hypoxic conditions, cells were exposed for $24 \mathrm{~h}$ to deferoxamine mesylate (DFX, $100 \mu \mathrm{M}$; Sigma-Aldrich), acting through inhibition of the HIF prolyl hydroxylases. Then, $100 \mathrm{nM}$ pituitary adenylate cyclase activating polypeptide-38 (cat no. A1439, SigmaAldrich) was added to U87MG cells $\left(50 \times 10^{4}\right.$ cells/dish 75) for $24 \mathrm{~h}$ in cells cultured in normoxia or hypoxia mimetic conditions. The treatment with the hypoxia-mimetic iron chelator DFX, as compared to the cell incubation method in hypoxic chamber, offers the advantage to the experimenter to open the culture plate/dish/flask many times without altering the hypoxic condition. However, DFX treatment reproduces a hypoxic event less relevant to that triggered by the use of a hypoxic chamber since it does not directly interfere with the oxygen levels.

\subsection{ELISA}

VEGF-A release in conditioned media were measured using the ELISA sandwich enzymatic method with a specific anti-VEGF-A antibody (RayBio human VEGF-A; Cat. No. ELH-VEGF; RayBiotech Life, Inc., Peachtree Corners, GA, USA) coated on a 96-well plate, according to the manufacturer's guidelines. Briefly, confluent U87MG cells grown in media supplemented with $1 \%$ FBS were treated for $24 \mathrm{~h}$ with DFX with or without PACAP. Standards or supernatants from samples were pipetted into the wells containing the immobilized anti-VEGF-A antibody. The wells were then washed before adding biotinylated anti-human VEGF antibody. Following incubation, the unbound biotinylated antibody was washed off, and HRP-conjugated streptavidin was pipetted in each well. After an additional wash step, a 3,3',5,5'-tetramethylbenzidine (TMB) substrate solution was added to each well, resulting in blue coloration proportional to the amount of bound VEGF. Finally, the stop solution was added, and the colorimetric intensity of the blue substrate, now turned yellow, was measured at $450 \mathrm{~nm}$. The mean absorbance was calculated for each 
set of duplicate standards, controls and samples, and the average zero standard optical density was subtracted.

\subsection{Wound Healing Assay}

U87MG cells grown to confluence in six-well dishes $\left(5 \times 10^{4}\right.$ cells $/$ well $)$ were scratched with a $200-\mu \mathrm{L}$ pipette tip, and wound closure was followed. Cells were incubated in $1 \%$ serum medium with or without PACAP either in normoxia or under hypoxia mimetic condition. Quantitative assessment of the wound area was performed under an inverted microscope, as previously described [60]. The distance that the advancing cells had moved into the cell-free (wound) area was measured after $24 \mathrm{~h}$. The migration was calculated as the average number of cells observed in three random of high-power wounded fields per well in duplicate wells and expressed in percentage of control (\% of control).

\subsection{Conditioned Medium and Preparation and Tube Formation Assay}

Sub-confluent U87MG cell cultures $\left(25 \times 10^{4}\right.$ cells/dish 75) were placed in media supplemented with 1\% FBS (conditioned medium 1-CM1; control) or containing $100 \mathrm{nM}$ of PACAP (CM2) or $100 \mu \mathrm{M}$ DFX (CM3) or DFX plus PACAP (CM4) and incubated at $37^{\circ} \mathrm{C}$ for $24 \mathrm{~h}$. After that, the CMs were collected and centrifuged at $2000 \mathrm{rpm}$ for $5 \mathrm{~min}$, and the supernatants were frozen at $-80^{\circ} \mathrm{C}$ until use. GeltrexTM reduced growth factor basement membrane matrix (Invitrogen, Carlsbad, CA, USA) was thawed at $4{ }^{\circ} \mathrm{C}$ overnight before use. GeltrexTM matrix was added to a 24 -well plate $(95 \mu \mathrm{L} /$ well $)$ and then incubated at $37^{\circ} \mathrm{C}$ for $30 \mathrm{~min}$ to allow polymerization. Murine microvascular endothelial cells (H5V) $\left(3 \times 10^{4}\right.$ cells/well) were starved overnight in the growth medium; then, the cells were seeded onto the layer of GeltrexTM matrix and cultured with $200 \mu \mathrm{L}$ of CM1, CM2, CM3 or $\mathrm{CM} 4$ at $37^{\circ} \mathrm{C}$ for $24 \mathrm{~h}$. Five randomly selected fields of view were captured with a digital camera (Canon, Tokyo, Japan) attached to an inverted microscope (Axio Observer A1; Carl Zeiss, Göttingen, Germany). Tube numbers were calculated as the average tube numbers per fields in duplicate for each well and calculated as percentage of control.

\subsection{Western Blot Analysis}

Proteins were extracted from total cells lysate, as previously described by D'Amico et al. [61]. Briefly, a buffer containing $20 \mathrm{mM}$ Tris (pH 7.4), 2 mM EDTA, 0.5 mM EGTA; $50 \mathrm{mM}$ mercaptoethanol, $0.32 \mathrm{mM}$ sucrose and a protease inhibitor cocktail (Roche Diagnostics, Monza, Italy) was added to U87MG cells adhering to the well using a Teflon-glass homogenizer and then sonicated twice for $20 \mathrm{sec}$ using an ultrasonic probe. Protein concentrations were determined by the Quant-iT Protein Assay Kit (Invitrogen). About $20 \mu \mathrm{g}$ of protein homogenate was diluted in $2 \mathrm{X}$ Laemmli buffer (Invitrogen), heated at $70{ }^{\circ} \mathrm{C}$ for $10 \mathrm{~min}$, separated on a Biorad Criterion XT 4-15\% Bis-tris gel (Invitrogen) by electrophoresis and then transferred to a nitrocellulose membrane (Invitrogen). Blots were blocked using the Odyssey Blocking Buffer (Li-Cor Biosciences, Lincoln, NE, USA). The transfer was monitored by a pre-stained protein molecular weight marker (BioRad Laboratories, Segrate, MI, Italy). Immunoblot analysis was performed by using specific antibodies: rabbit polyclonal anti-MMP2 (cat. no. ab97779, Abcam, Cambridge, MA, USA); rabbit polyclonal anti-MMP9 antibody (cat. no. ab38898, Abcam); rabbit polyclonal anti-Vimentin antibody (cat. no. ab137321, Abcam); goat polyclonal anti-VEGF (cat. no. sc-1836, Santa Cruz Biotechnology, Dallas, TX, USA), rabbit polyclonal anti-ZO-1 (cat. no. 61-7300, Thermo Fisher, MA, USA) and rabbit polyclonal anti- $\beta$-tubulin (cat n.sc-9104, Santa Cruz Biotechnology). The secondary antibodies goat anti-rabbit IRDye 800CW (cat \#926-32211; Li-Cor Biosciences), donkey anti-goat IRDye 800CW (cat \#926-32214; Li-Cor Biosciences) and goat anti-mouse IRDye 680CW (cat \#926-68020D, Li-Cor Biosciences) were used, respectively, at 1:20,000 and 1:30,000. Blots were scanned with an Odyssey Infrared Imaging System (Odyssey), as previously described by Maugeri et al. [62]. Densitometric analyses of Western blot signals were performed by using the ImageJ software 1.8.0_172 (NIH, Bethesda, MD, USA; 
available at http:/ /rsb.info.nih.gov/ij/index.html; last access date 28 April 2021). Values were normalized to $\beta$-tubulin used as loading control.

\subsection{Immunolocalization}

To determine the cellular distribution of PACAP, PAC1R, HIF- $1 \alpha$, vimentin, zonula occludens-1 (ZO-1), MMP-2 and CD44 proteins, immunofluorescence analysis was performed as previously described by $\mathrm{D}^{\prime}$ Amico et al. [63]. Fresh-frozen sections of a surgically resected tumor included in OCT were cut and fixed in $4 \%$ paraformaldehyde for $30 \mathrm{~min}$. Then, they were permeabilized with $0.2 \%$ Triton X100. To reduce non-specific staining, sections were treated with $1 \%$ bovine serum albumin (BSA) in PBS for $1 \mathrm{~h}$ and incubated overnight at $4{ }^{\circ} \mathrm{C}$ with anti-PACAP (1:100), anti-PAC1R (1:100) and anti-HIF-1 $\alpha$ (1:50) and anti-Vimentin (1:50), anti-ZO-1 (1:50) and anti-MMP-2 (1:50) antibodies. Cells were cultured on glass cover slips, fixed in $4 \%$ paraformaldehyde in phosphate-buffered saline (PBS; 15 min at room temperature), permeabilized with $0.2 \%$ Triton X-100, blocked with $0.1 \%$ BSA in PBS and then probed with anti-Vimentin (1:50), anti-ZO-1 (1:50) and anti-CD44 (1:50) antibodies. Signals were, respectively, revealed with Alexa Fluor 488 goat anti-rabbit or Alexa Fluor 594 goat anti-mouse for $1.5 \mathrm{~h}$ at room temperature (shielded from light). DNA was counterstained with 4,6-diamidino-2-phenylindole (DAPI; cat. no 940110, Vector Laboratories, Burlingame, CA, USA). After a series of washes in PBS and double-distilled water, the fixed cells were cover-slipped with Vectashield mounting medium (Vector Laboratories). Immunolocalization was analyzed by confocal laser scanning microscopy (Zeiss LSM700, Zeiss Oberkochen Germany). Green and blue signals were, respectively, detected with laser light at $488 \mathrm{~nm} / 10 \mathrm{~mW}$ and $405 \mathrm{~nm} / 5 \mathrm{~mW}$ by using the objective "PLANAPOCHROMAT" $63 \times / 1.40$ OIL DIC M27. Each scan was individually digitalized by a high sensitivity photomultiplier tube using the following acquisition setup: Gain master: 776; digital offset: -202; digital gain: 1.0. All acquisitions were performed with ZEN-2010 software [64].

\subsection{Statistical Analysis}

Data are represented as mean \pm standard error (SEM). One-way analysis of variance (ANOVA) was used to compare differences among groups and statistical significance was assessed by the Tukey-Kramer post hoc test. Colocalization of PACAP and PAC1R with HIF- $1 \alpha$ was analyzed using Mander's overlap coefficient and unpaired t-tests. The level of significance for all statistical tests was set at $p \leq 0.05$.

\section{Results}

\subsection{PACAP and PAC1R Expression in GBM Hypoxic Area}

To investigate the peptide and receptor expression in the hypoxic area of the tumor, we analyzed the co-localization of PACAP or PAC1R with HIF- $1 \alpha$ on human GMB sections by double-immunofluorescence analysis. In Figure 1, we highlighted with a white square the hypoxic area showing higher HIF-1 $\alpha$ expression in contrast to a non-hypoxic area limited by a yellow square representing a region with a weak HIF-1 $\alpha$ expression. As shown in Figure 1a,c, PACAP and PAC1R are present in the hypoxic region since they co-localize with HIF- $1 \alpha$, the hypoxia biomarker. However, the peptide and receptor were also detected in the non-hypoxic areas showing a weak HIF- $1 \alpha$ expression. To quantify PACAP and PAC1R expression in hypoxic or non-hypoxic area, we performed analysis of immunofluorescence signals by using Pearson correlation coefficient and the Mander's overlap coefficient. As shown in the graph bar of Figure 1b, PACAP/HIF- $1 \alpha$ colocalization was markedly reduced in the non-hypoxic GBM area as compared to hypoxic area (*** $p<0.001$ vs. hypoxic area). No significant difference was detected in PAC1R/HIF-1 $\alpha$ colocalization in hypoxic or weak hypoxic GBM area. 

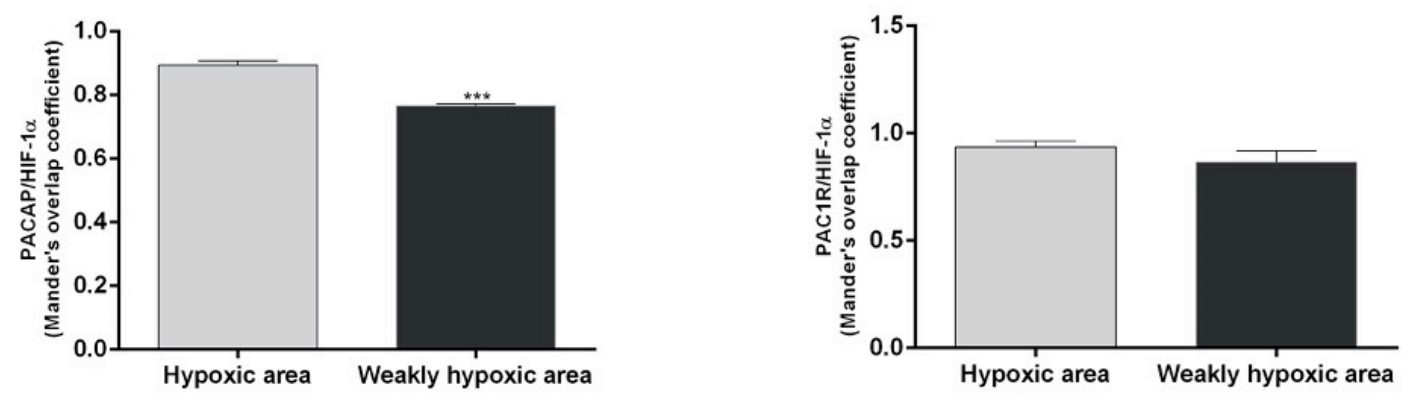

a

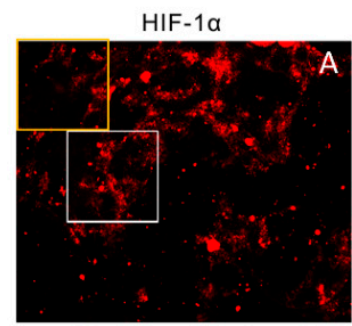

c

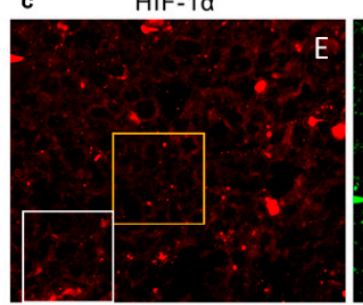

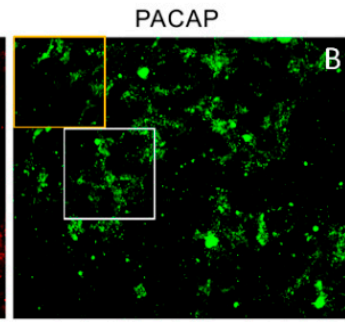

PAC1R

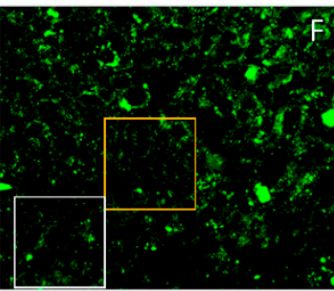

DAPI

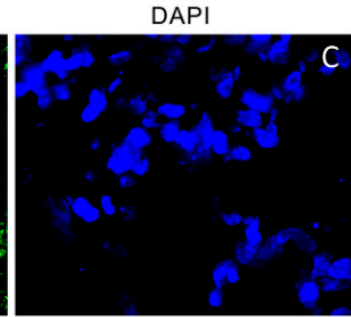

DAPI

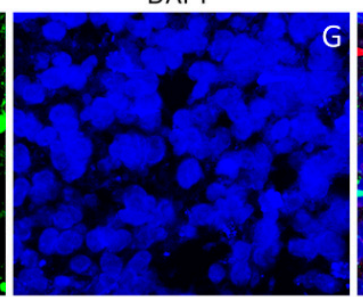

Merge

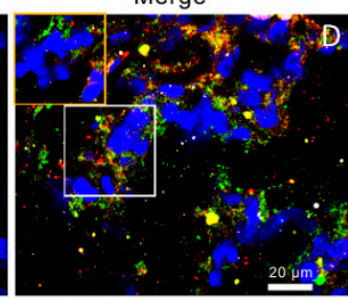

Merge

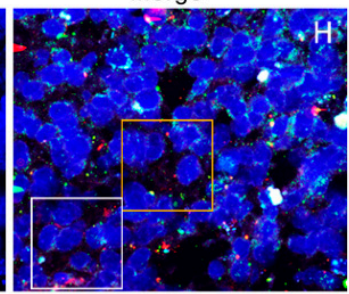

Figure 1. Expression of PACAP and PAC1R in hypoxic area of human GBM sections. (a,c) Representative photomicrographs showing PACAP (panel B, green), PAC1R (panel F, green), and HIF-1 $\alpha$ expression (panels A and E, red) in fresh-frozen sections of a surgically resected GBM. Nuclei were stained with DAPI. The white square indicates a representative hypoxic area showing a higher HIF- $1 \alpha$ expression in contrast to a non-hypoxic area limited by a yellow square representing a region with a weak HIF-1 $\alpha$ expression. Photomicrographs are representative results of fields taken randomly from each slide and scanned by confocal laser scanning microscopy (CLSM; Zeiss LSM700). (b,d) PACAP/HIF- $1 \alpha$ and PAC1R/HIF- $1 \alpha$ expression in hypoxic and weakly hypoxic regions were analyzed by using Mander's overlap coefficient. Data represent mean \pm S.E.M. $(* * * p<0.001)$.

To further deepen our analysis, we evaluated the co-localization of HIF- $1 \alpha$ and PACAP or PAC1R in cells co-expressing them. The serial section confocal microphotographs reported in Figure 2 allowed us to visualize the sub-cellular co-localization of PA-CAP/PAC1R and HIF- $1 \alpha$ in the nucleus (Figure 2, panel a A-H; Figure 2, panel b A-I), perinucleus (Figure 2, panel a I-M; Figure 2, panel b J,K) and cytoplasm (Figure 2, panel a N-T; Figure 2, panel b L-T). As expected, HIF-1 $\alpha$ immunoreactivity was detected in all cellular compartments of tumor cell (Figure 2, panel a and b). Interestingly, the double-immunofluorescence analysis showed a cytoplasmic, perinuclear and nuclear colocalization of HIF-1 $\alpha /$ PACAP (Figure 2, panel a) or HIF-1 $\alpha /$ PAC1R (Figure 2, panel b), confirming a close association among PACAP/PAC1R expression and hypoxic microenvironment. To better visualize the signal of the peptide and the relative receptor, in microphotograph $\mathrm{H}^{\prime \prime}$ was highlighted nuclear localization of PACAP, whereas microphotograph $\mathrm{M}^{\prime \prime}$ reported nuclear localization of PAC1R and their merging signal with HIF- $1 \alpha$. 

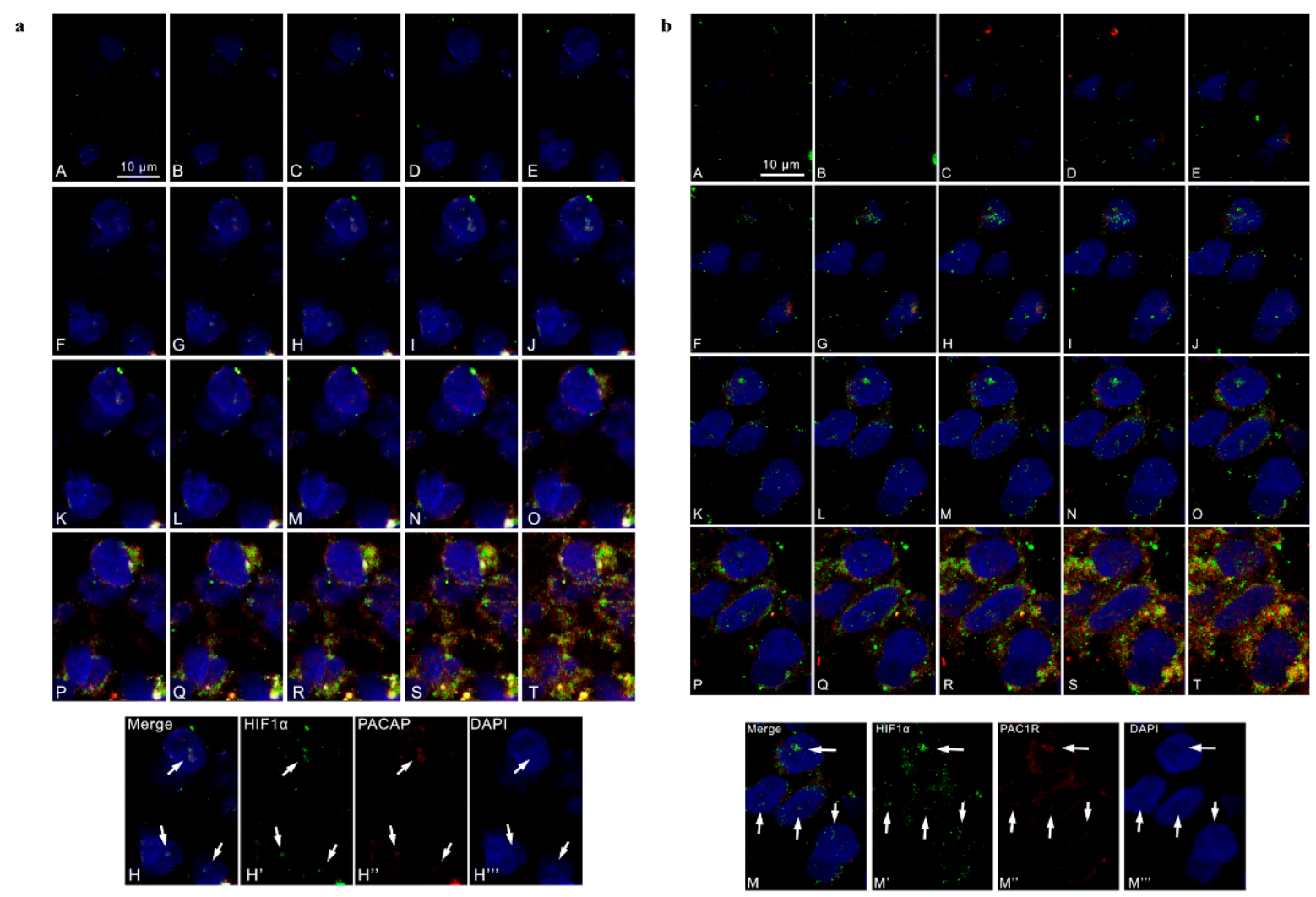

Figure 2. Cellular co-localization of PACAP, PAC1R and HIF-1 $\alpha$ in human GBM serial sections. Representative photomicrographs showing the cellular co-localization of HIF- $1 \alpha$ and PACAP or PAC1R. (a) Green, red and blue correspond to HIF-1 $\alpha$, PACAP and DAPI respectively. $\mathrm{H}^{\prime}, \mathrm{H}^{\prime \prime}$ and $\mathrm{H}^{\prime \prime \prime}$ in the panel $\mathrm{c}$ show the red, green and blue channels corresponding to a section positioned in the middle part of the $\mathrm{z}$ axis. The white arrows indicate the co-localization of HIF- $1 \alpha$ and PACAP in the cell nuclei. Scale bar is $10 \mu \mathrm{m}$. (b) Green, red and blue correspond to HIF1 $\alpha$, PAC1R and DAPI respectively. M', M" and $\mathrm{M}^{\prime \prime \prime}$, in the panel $\mathrm{d}$, show the red, green and blue channels corresponding to a section positioned in the middle part of the $\mathrm{z}$ axis. The white arrows indicate the co-localization of HIF1 $\alpha$ and PAC1R in the cell nuclei. Scale bar is $10 \mu \mathrm{m}$.

\subsection{PACAP Effect on VEGF Production in GBM Cells Exposed to DFX-Induced Hypoxia}

To characterize the functional role of PACAP and its receptor on neo-angiogenesis induced by the hypoxic tumor micro-environment, we investigated the effect of the peptide on U87MG cells exposed to DFX. In our previous work, we have demonstrated that PACAP treatment reduced HIF-1 $\alpha$ expression in U87MG cells exposed to DFX-induced hypoxia [17]. Since neo-angiogenesis process triggered by low oxygen tension levels is closely associated to VEGF production and release, here we investigated whether PACAP interfered with VEGF expression and secretion in U87MG cells exposed to hypoxic mimetic agent, DFX. As shown in Figure 3, the expression of VEGF was significantly increased in GBM cells following the hypoxic insult (**** $p<0.0001$ vs. CTRL). The peptide treatment induced significant reduction of intra-cellular VEGF levels in hypoxic condition ${ }^{\#} p<0.05$ and \#\#\# $p<0.0001$ vs. DFX). Hypoxia mimetic condition also increased secretion of VEGF in supernatant of U87MG cells (**** $p<0.0001$ vs. CTRL; Table 1 ), whereas PACAP treatment significantly reduced the growth factor releases in culture medium as demonstrated by ELISA assay (\#\#\# $p<0.001$ vs. DFX; Table 1$)$. 


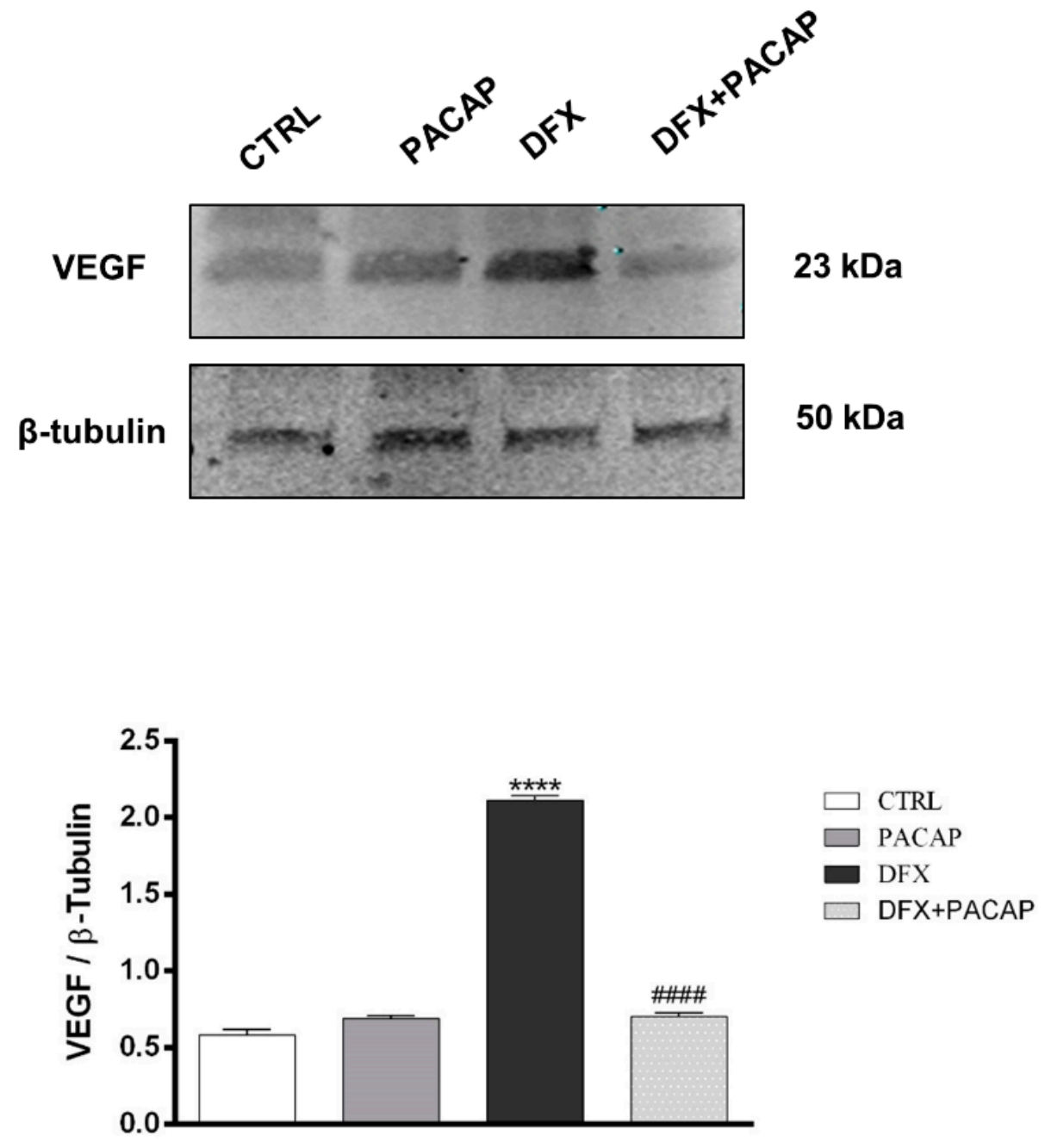

Figure 3. PACAP effect on VEGF expression in human GBM cells exposed to DFX-induced hypoxia. The expression of VEGF was evaluated in U87MG cells treated with vehicle or $100 \mathrm{nM}$ of PACAP or DFX or DFX plus PACAP for $24 \mathrm{~h}$ through Western blot analysis. The bar graphs show quantitative analysis of signals obtained by immunoblots resulting from three independent experiments. Relative band densities were quantified by using ImageJ software. Protein levels are expressed as arbitrary units obtained following normalization to $\beta$-tubulin, which was used as loading control. Data represent means \pm SEM. ${ }^{* * * *} p<0.0001$ vs. CTRL; ${ }^{\# \# \# ~} p<0.0001$ vs. DFX.

Table 1. VEGF content in conditioned medium from U87MG cells. VEGF levels were detected in supernatants and expressed in $\mathrm{pg} / \mathrm{mL}$. Data resulting from three independent experiments are represented as means $\pm \mathrm{SEM} .{ }^{* * *} p<0.0001 \mathrm{vs}$. CTRL; \#\#\# $p<0.001$ vs. DFX.

\begin{tabular}{|c|c|c|c|c|}
\hline $\begin{array}{c}\text { U87MG Cell } \\
\text { Line-Derived } \\
\text { Conditioned Media }\end{array}$ & $\begin{array}{c}\text { CM1 } \\
\text { (Vehicle) } \\
\text { Mean } \pm \text { SEM }\end{array}$ & $\begin{array}{c}\text { CM2 } \\
\text { (PACAP) } \\
\text { Mean } \pm \text { SEM }\end{array}$ & $\begin{array}{c}\text { CM3 } \\
\text { (DFX) } \\
\text { Mean } \pm \text { SEM }\end{array}$ & $\begin{array}{c}\text { CM4 } \\
(\text { DFX + PACAP) } \\
\text { Mean } \pm \text { SEM }\end{array}$ \\
\hline VEGF (pg/mL) & $6584 \pm 9.85$ & $6041 \pm 5.77^{* * * *}$ & $7203 \pm 8.54^{* * * *}$ & $7013 \pm 11.55$ \#\#\# \\
\hline
\end{tabular}

In Table 1, we reported VEGF concentration calculated in each conditioned medium derived from U87MG cells cultured with vehicle (CM1), PACAP (CM2), DFX (CM3) and DFX + PACAP (CM4). 


\subsection{PACAP Reduces New Vessels Formation Induced by Conditioned Media from GBM Cell Cultures}

VEGF secretion in tumor micro-environment leads to neo-angiogenesis. To examine whether PACAP is able to counteract this process, we tested the effect of peptide in a model in vitro of $\mathrm{H} 5 \mathrm{~V}$ cells forming a network of tube-like structures mimicking neo-vessels formation. Cells were cultured with $200 \mu \mathrm{L}$ of CM1, CM2, CM3 or CM4 for $24 \mathrm{~h}$. As shown in Figure 4, incubation of H5V cells with CM3, derived from U87MG cells cultured with DFX and containing $7203 \mathrm{pg} / \mathrm{mL}$ VEGF, significantly increased the number of tube-like structures as compared to vehicle treated GBM cells (**** $p<0.0001$ vs. CM1). In contrast, H5V cells cultured with CM4 containing $7013 \mathrm{pg} / \mathrm{mL}$ VEGF formed fewer number of tube-like structures as compared to cells grown in CM3 ( $p<0.0001$ vs. CM3). This result confirmed that the peptide decreases the release of VEGF in the GBM hypoxic micro-environment by reducing new vessels formation.

CM1

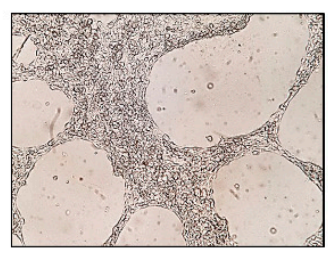

CM2

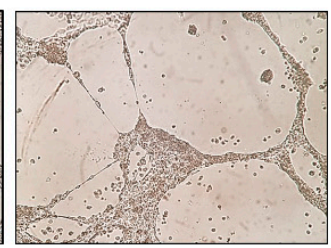

CM3

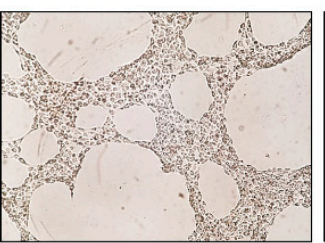

CM4

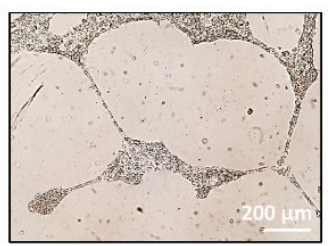

b

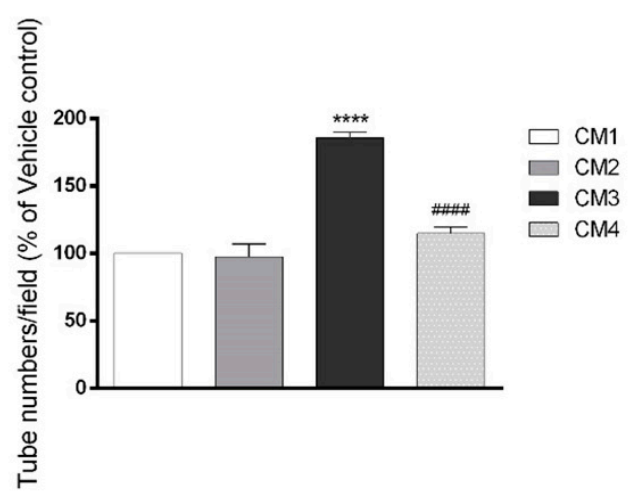

Figure 4. Effect of PACAP on new vessels formation. (a) Representative results of tube formation assay. H5V cells were cultured with $200 \mu \mathrm{L}$ of conditioned medium derived from U87MG cells treated with vehicle (CM1), PACAP (CM2), DFX (CM3) or DFX plus PACAP (CM4). The tubes were visualized under a microscope for quantification and calculated as the average tube numbers per field in duplicate for each well. (b) In the bar graph, values are expressed as percentage of control (**** $p<0.0001$ vs. CTRL; \#\#\# $p<0.0001$ vs. DFX).

\subsection{PACAP Counteracts the Hypoxia Mimetic Condition-Induced EMT in U87MG Cells}

GBM is a heterogeneous tumor containing different cell types. In particular, its aggressiveness is associated with the EMT process characterized by the conversion of epithelial cancer cells toward the undifferentiated mesenchymal phenotype. To confirm this evidence, we have analyzed the expression of two EMT markers in human GBM sections: vimentin and ZO-1. Vimentin, representing a specific mesenchymal marker, is the major element of the intermediate filament family of proteins and is ubiquitously expressed in normal mesenchymal cells, regulating the maintenance of cell integrity and resistance. Its expression increased in different cancers including GBM [65]. On the contrary, the ZO-1 marker is involved in the assembly of tight and adherent junctions of epithelial cells. In tumor cells, ZO-1 expression decreased following the activation of EMT [66]. As shown in Figure 5a, vimentin was detected in some cells surrounding others expressing ZO-1 (Figure 5a). To characterize the cellular expression of PACAP and PAC1R in human GBM, we have also analyzed their co-localization with vimentin and another mesenchymal 
marker, MMP-2. As shown in Figure 5b,c, some cells were positive for vimentin and MMP-2, whereas the peptide and its receptor were also diffusely localized in cells immunonegative to mesenchymal markers. This result suggested that PACAP and PAC1R were expressed in cells with different phenotypes. Previous works have shown that the EMT process is favored by the hypoxic environment [18,19].
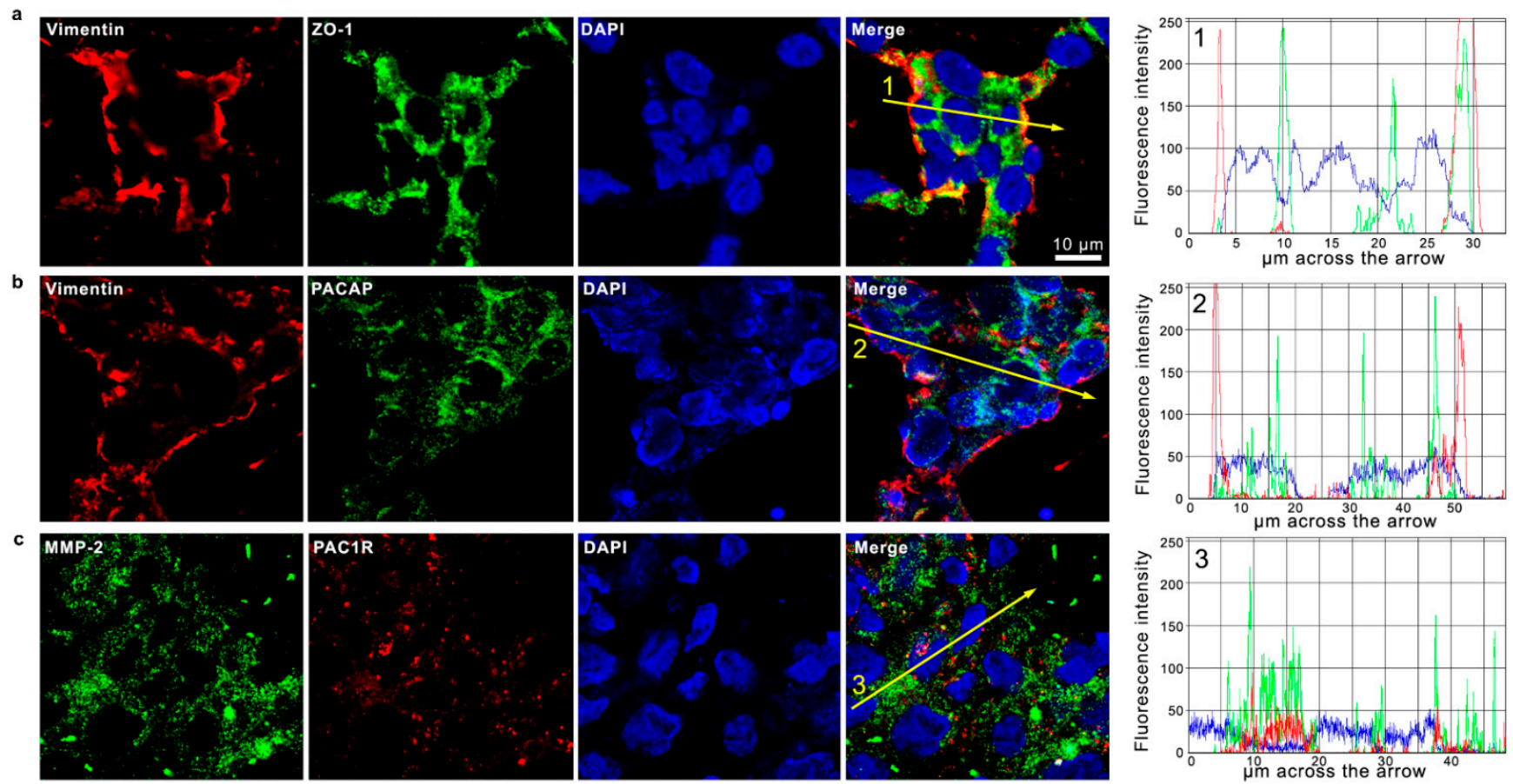

Figure 5. Co-expression of PACAP and PAC1R with EMT-related markers in human GBM sections. Representative photomicrographs showing the cellular co-localization of Vimentin (red) with ZO-1 (green) (a); Vimentin (red) with PACAP (green) (b); and MMP-2 (green) with PAC1R (red) (c). Nuclei were stained with DAPI (blue). Photomicrographs are representative results of fields taken randomly from each slide and scanned by confocal laser scanning microscopy (CLSM; Zeiss LSM700). The graphs indicate the measured fluorescence intensity of the single channels across the arrow, allowing us to visualize the specific peaks of single the proteins or their co-expression detected by overlapped signals. Fluorescence intensity graphs were obtained with ZEN-20210 software.

To investigate the functional role played by PACAP on EMT process hypoxia induced, we have studied its effect on U87MG cells exposed to DFX. As shown in Figure 6a, the cell culture included different cell phenotypes, considering that some cells expressed ZO-1, whereas others expressed vimentin. The exposure to DFX induced the EMT event in U87MG cells, as demonstrated by the increased expression of vimentin in contrast to the down-regulation of ZO-1. To investigate whether PACAP was able to counteract the EMT event, we analyzed the expression of some specific markers in GBM cells treated with the peptide and exposed to hypoxia mimetic condition. As shown in Figure 6b, the U87MG cells after DFX insult exhibited higher expression of EMT markers including vimentin, MMP-2 and MMP-9 as compared to control (**** $p<0.0001$ vs. CTRL). On the contrary, low levels of ZO-1 epithelial marker were detected in DFX group $\left({ }^{* *} p<0.01\right.$ vs. CTRL). The treatment with PACAP of cells grown under hypoxia mimetic condition significantly decreased the expression of vimentin, MMP-2 and MMP-9, with a simultaneous increase in ZO-1 expression respect to DFX group ( ${ }^{\# \# \# ~} p<0.0001$ vs. DFX) (Figure 6b). 
To evaluate whether PACAP affects GBM cells migration following hypoxic insult, we have performed wound healing assay. As shown in Figure 7, U87MG cells motility drastically increased after exposure to DFX for $24 \mathrm{~h}$ as compared to control ${ }^{* * * *} p<0.0001$ vs. CTRL). Instead, fewer cells grown under hypoxia mimetic condition moved toward the wounded area after PACAP-treatment $\left({ }^{\# \# \#} p<0.0001\right.$ vs. DFX).
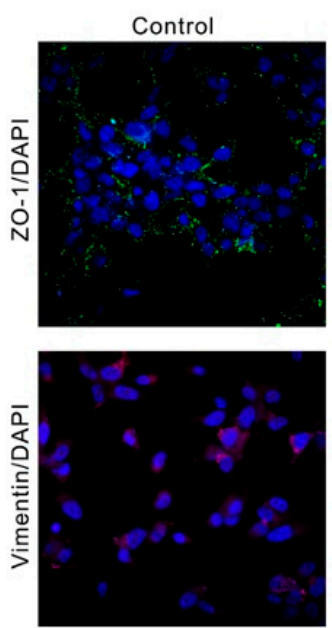
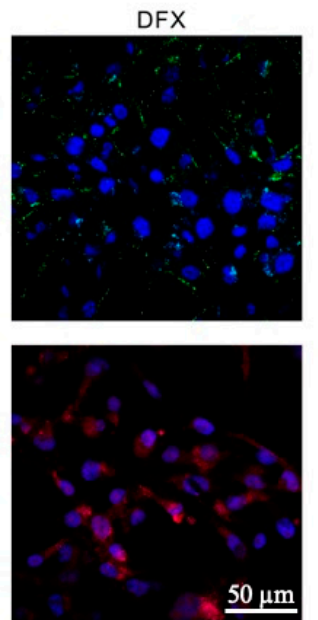
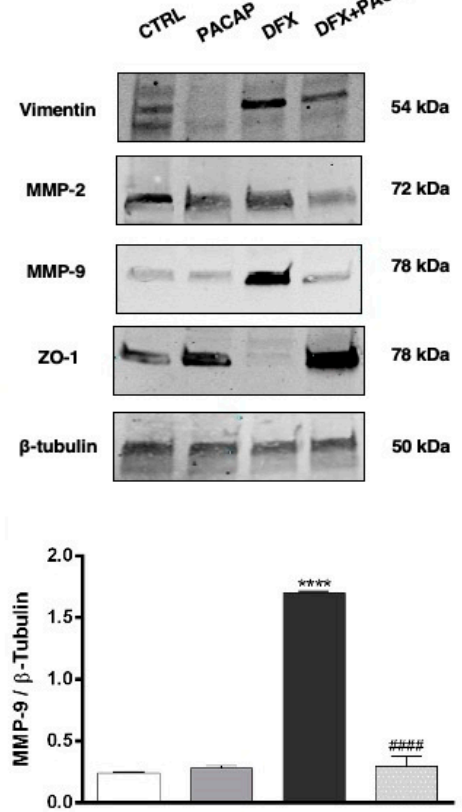
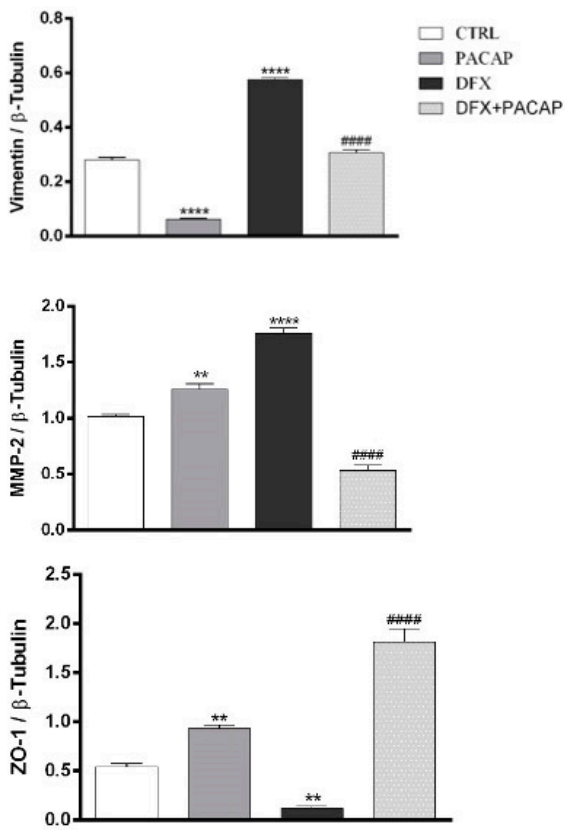

Figure 6. PACAP effect on EMT markers in human GBM cells exposed to DFX-induced hypoxia. (a) Immunosignal of ZO-1 (green) and Vimentin (red) expression in U87MG cells cultured in normal oxygen tension levels (control) or in hypoxic condition (DFX) for $24 \mathrm{~h}$. The ZO-1 and Vimentin signals were detected using specific primary antibodies revealed with the Alexa Fluor 488 secondary antibodies (green fluorescence), and Alexa Fluor 594 secondary antibodies (red fluorescence), respectively. Cell nuclei were stained with diamidino-2-phenylindole, DAPI (blue fluorescence). The photomicrographs are representative results taken from different fields in randomly selected slides and scanned by confocal laser scanning microscopy (CLSM). Scale bar $(50 \mu \mathrm{m})$. (b) Representative immunoblots of Vimentin, MMP-2, MMP-9 and ZO-1 protein expression on U87MG cells cultured with PACAP or DFX or DFX plus PACAP or vehicle for $24 \mathrm{~h}$. The bar graphs show quantitative analysis of signals obtained by immunoblots resulting from three independent experiments. Relative band densities were quantified by using ImageJ software. Protein levels are expressed as arbitrary units obtained after normalization to $\beta$-tubulin, which was used as loading control. Data represent means $\pm \mathrm{SEM}$. ${ }^{* *} p<0.01$ and ${ }^{* * * *} p<0.0001$ vs. CTRL; ${ }^{\# \# \# ~} p<0.0001$ vs. DFX.

To characterize the phenotype of migrant cells along the scratch, we have evaluated the expression of vimentin and CD44 through immunofluorescence analysis. CD44 exerts a key role in GBM invasion [67]. In fact, it has recently demonstrated that GBM cells engage and invade hyaluronic acid-rich matrix through micro-tentacles expressing CD44 receptor [68]. As shown in Figure 8a, an abundant invasion of wound area by cells expressing high levels of CD44 and Vimentin has been observed under hypoxia mimetic condition. Interestingly, PACAP treatment reduced the migratory ability of mesenchymal cells exposed to DFX-induced hypoxia, as demonstrated by the reduced expression of both EMT makers (Figure 8a-c; ${ }^{* * *} p<0.0001$ ). 


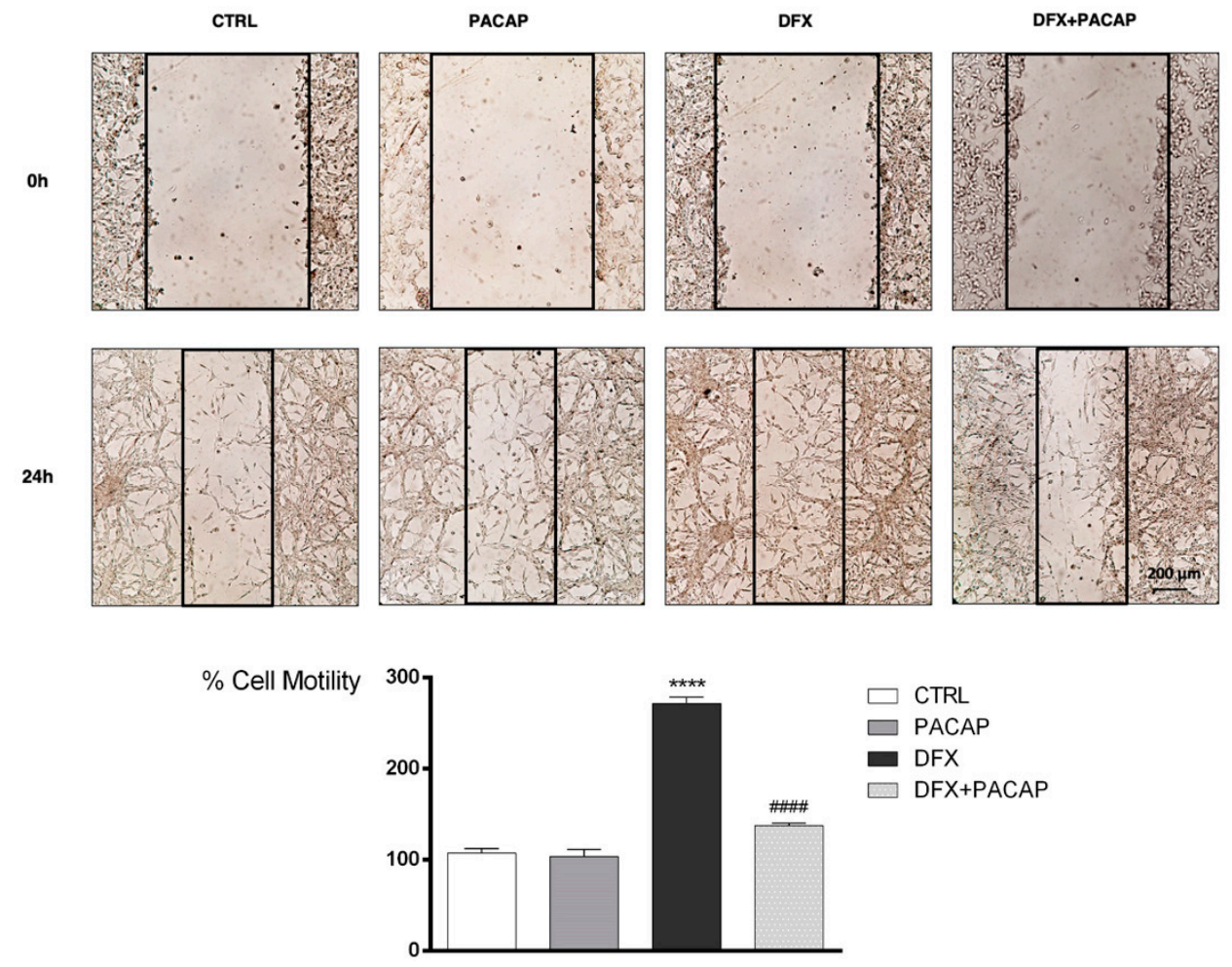

Figure 7. PACAP effect on GBM cells migration following DFX-induced hypoxic insult. Cell monolayer was scraped by a pipette. The wounded areas were visualized under a microscope for quantification. Migration was calculated as the average number of cells observed in five random wounded fields per well in duplicate wells. In the bar graph, values are expressed as percentage of control. **** $p<0.0001$ vs. CTRL; ${ }^{\# \# \# ~} p<0.0001$ vs. DFX.
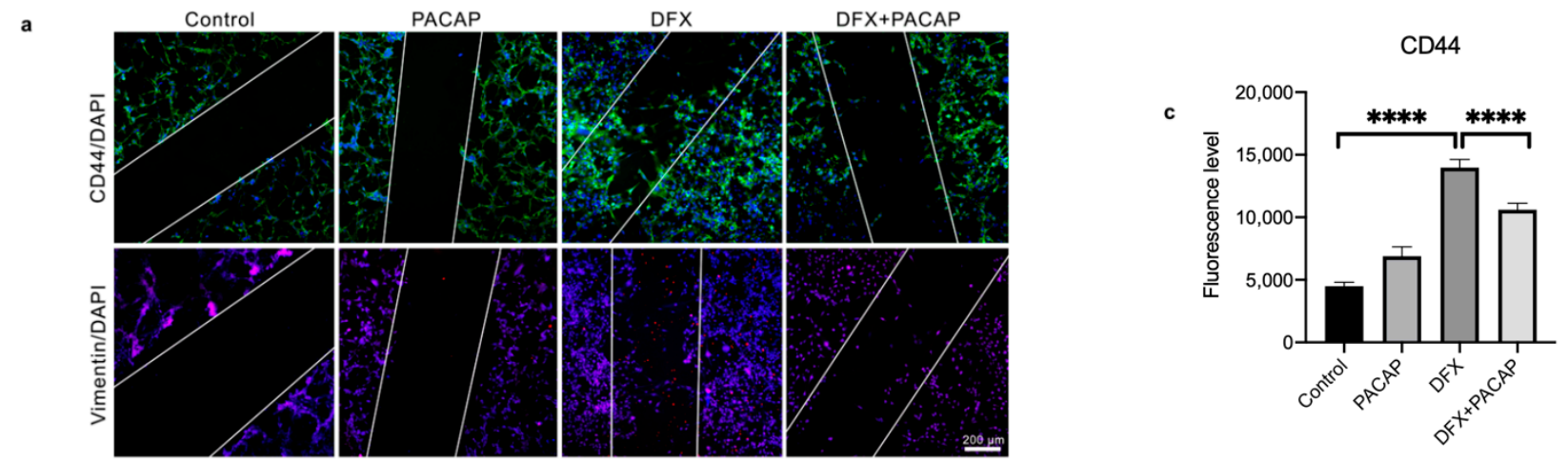

b
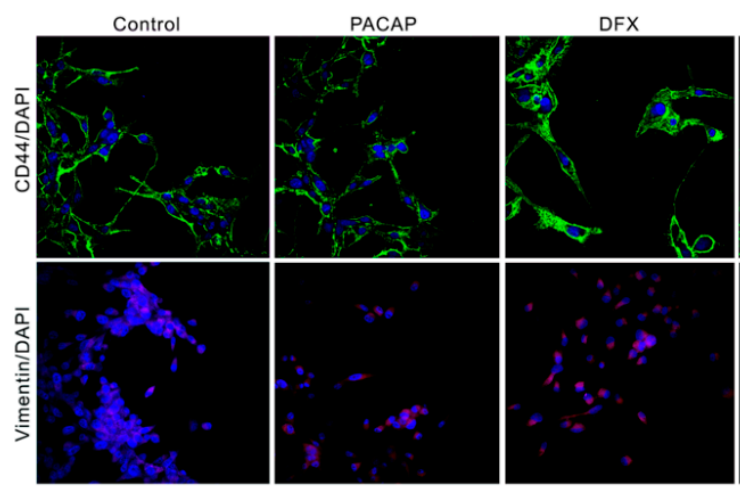

DFX+PACAP
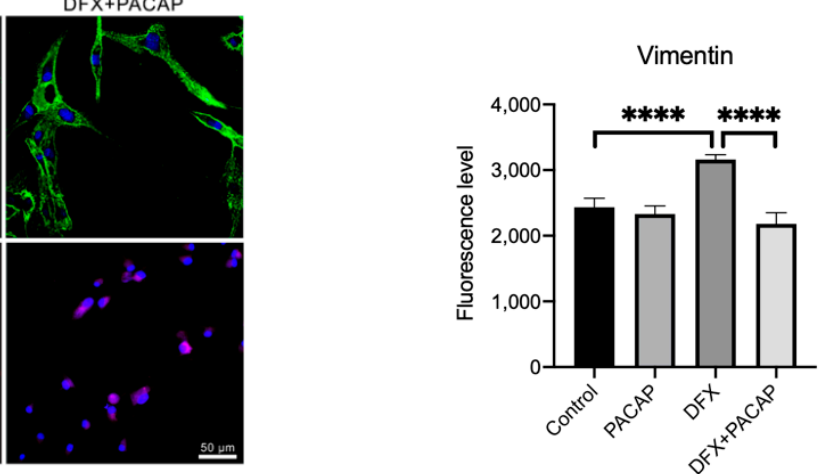

Figure 8. PACAP effect on CD44 and Vimentin expression in migrating GBM cells exposed to hypoxia mimetic conditions. Immunosignal of CD44 and Vimentin protein in U87MG cells cultured with PACAP or DFX or DFX plus PACAP or vehicle 
for 24 h. (a,b) The CD44 and Vimentin signals were detected using specific primary antibodies revealed with the Alexa Fluor 488 secondary antibodies (green fluorescence) and Alexa Fluor 594 secondary antibodies (red fluorescence), respectively. Cell nuclei were stained with diamidino-2-phenylindole, DAPI (blue fluorescence). The photomicrographs in panel $\mathrm{b}$ represent randomly acquired images from regions surrounding the wound area. Panels a and $\mathrm{b}$ show representative results taken from different fields in randomly selected slides and scanned by confocal laser scanning microscopy (CLSM). Scale bars $(200$ and $50 \mu \mathrm{m})$. (c) Fluorescence intensities graphs were obtained with the "Profile view" function of ZEN-2011 software; the fluorescence red, green and blue were read for each pixel along the lines, and the graphs reflect, in arbitrary units, the proportion of the pixel intensity in the three wavelengths. Data represent means $\pm \operatorname{SEM}(* * * *<0.0001)$.

\section{Discussion}

GBM, the most common and fatal type of brain tumor, is characterized by high degree of cellular heterogeneity and the strong ability to invade the surrounding tissue. GBM contains areas of intra-tumor necrosis that are typically associated to extensive hypoxic foci. The hypoxic event is principally mediated by HIFs, whose activation induces the transcription of a wide variety of genes involved in several pathways such as glycolysis, angiogenesis, invasion and EMT, all events playing a crucial role in GBM aggressiveness [19]. Our previous study showed that PACAP counteracts the expression of HIFs via PI3K/AKT and MAPK/ERK pathways inhibition [17]. In the present work, we demonstrated that PACAP is mainly expressed in hypoxic areas as compared to weakly hypoxic regions of human GBM (Figure 1a,b). On contrary, PAC1R is diffusely localized in the tumor bulk (Figure 1c,d). In the cell, PACAP/PAC1R showed co-localization with HIF-1 $\alpha$ both in the cytoplasm and nucleus (Figure 2). In accord, Yu et al. [69] has previously described the translocation of PAC1R from cytoplasm into the nucleus based on PACAP concentration. At low concentration, the peptide induced the dimerization of PAC1R on perinuclear membrane, whereas at high concentration it promoted translocation of PAC1R dimers into the nucleus triggering different cell signaling. Furthermore, some insults caused up-regulation of PAC1R and its nuclear translocation to protect cells against oxidative stress damage [70]. The presence of PAC1R into the nucleus may be involved in a specific cell response to hypoxia. In accord, PACAP acts as negative regulator of HIF- $1 \alpha$ through the inhibition of PI3K/Akt and ERK1/2 signaling pathways, which interfere with HIFs expression [71-73]. Although further investigations are needed, the co-localization of HIF- $1 \alpha$ with PACAP and PAC1R in the nucleus prompts us to hypothesize that PACAP might inhibit HIF- $1 \alpha$ not only through suppression of PI3K/Akt and ERK1/2 pathways but also at activity levels through direct binding with HIF- $1 \alpha$ in the nucleus.

It is well-known that HIF- $1 \alpha$ plays a key role in the activation of angiogenic cascade by inducing the up-regulation of VEGF $[16,74]$. To investigate whether PACAP binding to its receptor in the hypoxic area could interfere with neo-angiogenesis, we have analyzed its effect on in vitro model of GBM cells exposed to DFX-induced hypoxia. As shown in Figure 3, VEGF was significantly up-regulated in cells grown under hypoxia mimetic condition as well as its secretion in the culture medium (Table 1). VEGF released in the extracellular micro-environment of GBM actively participates to aberrant angiogenesis. This event is promoted by migration of endothelial cells toward the extracellular matrix, where they adhere to each other by creating a lumen [75]. To confirm the key role exerted by hypoxic micro-environment in the angiogenic process, we cultured $\mathrm{H} 5 \mathrm{~V}$ endothelial cells in conditioned media from GBM cells exposed to hypoxia mimetic condition (CM3). The predicted prominent pro-angiogenic response has been confirmed by increased number of tubes formation, representing an in vitro model of blood vessels (Figure 4). The peptide treatment decreased the expression levels of VEGF as well as its release (Figure 3 and Table 1). This reduction affected the aberrant angiogenesis as demonstrated by the reduced number of micro-vessels observed when H5V cells were cultured with CM4 (Figure 4). Although VEGF is the primary inducer of angiogenesis released in U87MG CM [76,77], other factors concur to promote the angiogenic response. In accord, Pen et al. [78] showed that transforming growth factors (TGF)- $\beta 1$ and TGF- $\beta 2$ released in U87MG-CM induce the migration and invasion of glioma cells as well as the angiogenic event. As high- 
lighted in recent papers, hypoxia through HIF-1 $\alpha$ activation participates to increase cell stemness in tumor mass by promoting the EMT and addressing the GBM fate toward malignancy $[18,79,80]$. GBM is characterized by a high degree of cellular heterogeneity, including epithelial as well as mesenchymal cells. In accord, we have detected in the GBM tissue areas expressing vimentin-positive mesenchymal cells surrounding ZO-1-positive epithelial cells. Interestingly, PACAP and PAC1R are expressed in both cellular phenotypes (Figure 5).

Literature extensively showed that EMT process is promoted by hypoxia [18]. Therefore, we have investigated whether PACAP interferes with this event by analyzing its effect on GBM cells exposed to DFX. U87MG cell culture represents a useful model, in vitro, to study EMT, considering that it contains some cells expressing the epithelial marker ZO1, whereas some others bear the mesenchymal marker Vimentin (Figure 6a). Furthermore, transition toward the malignant phenotype is promoted in cells grown under hypoxia mimetic condition (Figure 6a). In accord, the number of Vimentin immune-positive cells increased after DFX treatment. These data have been confirmed by Western blot analysis. Beside up-regulation of vimentin and down-regulation of ZO-1, GBM cells exposed to hypoxic insult also shown an increased expression of matrix metalloproteinases (MMPs), such as MMP-2 and MMP-9, representing other markers of cellular mesenchymal phenotype (Figure 6b). Up-regulation of these proteins is involved in the degradation of the extracellular matrix and basement membrane, allowing GBM cells to spread to surrounding tissue [81]. It is noteworthy that PACAP interfered with EMT of GMB cells exposed to DFX-induced hypoxia down-regulating Vimentin, MMP-2 and MMP-9 protein levels while, on the other hand, restoring the expression levels of ZO-1 (Figure 6b). As shown in Figure 6b, DFX plus PACAP-treated cells displayed overexpression of ZO-1 as well as down-regulation of MMP-2 more intense compared to control group levels. In our previous paper, we observed a similar result related to $\mathrm{ZO}-1$ expression in retinal pigmented epithelial cells exposed to high glucose and DFX [33]. Although the mechanisms involved are still unknown, we cannot rule out that PACAP could interfere with the expression of these proteins under hypoxia.

Hypoxia increased cell invasive capacity as shown by wound healing assay. In fact, DFX treatment for $24 \mathrm{~h}$ increased the number of migrating cells in the wound area as compared to control group. PACAP treatment reduced cells migration along the lesioned region in respect to DFX treated group (Figure 7). Moreover, most migrating cells exposed to hypoxia mimetic condition showed a mesenchymal phenotype, as confirmed by their immune-positive signal for Vimentin and CD44, detected through immunofluorescences analysis (Figure 8). The key role of CD44 in regulation of EMT has been previously demonstrated [82]. It is a non-kinase transmembrane glycoprotein that acts as a receptor for hyaluronic acid, a major element of the extracellular matrix. Considering that the brain contains abundant levels of hyaluronic acid, CD44 could play important role in glioma cells' migration. In accord, CD44, highly expressed in 55.55\% of GBM, induces acquisition of more malignant abilities, and patients with higher levels of this glycoprotein exhibit a shorter survival time [83]. Here, we confirmed the ability of PACAP to prevent cells' invasiveness by reducing their transition toward the more malignant mesenchymal phenotype. In fact, the peptide treatment reduced the number of Vimentin and CD44 immuno-positive migrating cells (Figure 8). In vitro studies have some limitations since cells are not exposed to the complex biological condition characterizing the tissue in vivo. Therefore, we are planning to study the effects of this neuropeptide on GBM progression in vivo animal models. Moreover, in a future study, we are going to investigate the role of this peptide in GBM cells with different genotype. We have also carried out a preliminary study on T98G cells (Figure S1). Similarly to the results obtained in the U87MG cells, we found that PACAP affects VEGF expression and release in T98G cells exposed to DFX-induced hypoxia. Moreover, we detected a reduced number of tubes formed by $\mathrm{H} 5 \mathrm{~V}$ cells grown in conditioned medium derived from T98G cells. These cells bear a p53 mutation and a high MGMT activity and, as demonstrated in a recent paper, these 
genomic characteristics make them more resistance to Temozolomide (TMZ) treatment as compared to other GBM cells, such as A172 cells [84]. This investigation might underline the efficacy of the peptide in a combinatory therapy with TMZ for GBM treatment with a specific genotype. Although in the last years progress has been made in the treatment of GBM, patient survival is still very poor. The aggressive phenotype, the invasiveness and the resistance to chemotherapy and radiotherapy of GBM have been linked to its histopathological heterogeneity and multimodal events triggered by tumoral hypoxic micro-environment. The complex regulating mechanism carried out by PACAP might open a new avenue in the therapeutic approach to this fatal malignancy.

Supplementary Materials: The following are available online at https://www.mdpi.com/article/10 $.3390 /$ biomedicines9080965/s1, Figure S1: The effect of PACAP on angiogenic response in T98G cells exposed to DFX-induced hypoxia.

Author Contributions: All authors (G.M. (Grazia Maugeri), A.G.D., S.S., C.F., D.M.R., R.C., G.B., S.G., G.M. (Giuseppe Musumeci) and V.D.) reviewed the manuscript. Conceptualization, G.M. (Grazia Maugeri) and V.D.; Writing-Original Draft Preparation, G.M. (Grazia Maugeri), A.G.D. and V.D.; Investigation, G.M. (Grazia Maugeri), A.G.D., D.M.R., S.S. and C.F.; Writing-Review and Editing, G.M. (Grazia Maugeri), A.G.D. and V.D.; Resources, R.C.; Funding Acquisition, G.M. (Giuseppe Musumeci), A.G.D. and S.G. All authors have read and agreed to the published version of the manuscript.

Funding: This work was funded by the University Research Project Grant (PIACERI FoundNATURE-OA-2020-2022), Department of Biomedical and Biotechnological Sciences (BIOMETEC), University of Catania, 95123 Catania, Italy. This project was also supported by STARTING GRANT 2020 entitled, "Regulatory effect of PACAP-ADNP axis and its involvement in modulation of Glioblastoma multiforme", Department of Drug Science, University of Catania.

Institutional Review Board Statement: The study was approved by the local ethics committee of the Research Center on Motor Activities (CRAM), University of Catania (Protocol Number: CRAM015-2020, 16 March 2020).

Informed Consent Statement: Informed consent was obtained from the subject involved in the study. Written informed consent has been obtained from the patient to publish this paper.

Data Availability Statement: All data are available within the manuscript and upon request to the corresponding author.

Conflicts of Interest: The authors have no conflict of interest to declare.

\section{References}

1. Wen, P.Y.; Kesari, S. Malignant gliomas in adults. N. Engl. J. Med. 2008, 359, 92-507. [CrossRef] [PubMed]

2. Louis, D.N.; Perry, A.; Reifenberger, G.; von Deimling, A.; Figarella-Branger, D.; Cavenee, W.K.; Ohgaki, H.; Wiestler, O.D.; Kleihues, P.; Ellison, D.W. The 2016 World Health Organization Classification of Tumors of the Central Nervous System: A summary. Acta Neuropathol. 2016, 131, 803-820. [CrossRef] [PubMed]

3. Furnari, F.B.; Fenton, T.; Bachoo, R.M.; Mukasa, A.; Stommel, J.M.; Stegh, A.; Hahn, W.C.; Ligon, K.L.; Louis, D.N.; Brennan, C.; et al. Malignant astrocytic glioma: Genetics, biology, and paths to treatment. Genes Dev. 2007, 21, 2683-2710. [CrossRef] [PubMed]

4. McNeill, K.A. Epidemiology of brain tumors. Neurol. Clin. 2016, 34, 981-998. [CrossRef] [PubMed]

5. Rong, Y.; Durden, D.L.; Van Meir, E.G.; Brat, D.J. ‘Pseudopalisading' necrosis in glioblastoma: A familiar morphologic feature that links vascular pathology, hypoxia, and angiogenesis. J. Neuropathol. Exp. Neurol. 2006, 65, 529-539. [CrossRef]

6. Brat, D.J.; Van Meir, E.G. Glomeruloid microvascular proliferation orchestrated by VPF/VEGF: A new world of angiogenesis research. Am. J. Pathol. 2001, 158, 789-796. [CrossRef]

7. Maynard, M.A.; Ohh, M. Von Hippel-Lindau tumor suppressor protein and hypoxia-inducible factor in kidney cancer. Am. J. Nephrol. 2004, 24, 1-13. [CrossRef]

8. Scuderi, S.; D’amico, A.G.; Federico, C.; Saccone, S.; Magro, G.; Bucolo, C.; Drago, F.; D'Agata, V. Different Retinal Expression Patterns of IL-1 $\alpha$, IL-1 $\beta$, and Their Receptors in a Rat Model of Type 1 STZ-Induced Diabetes. J. Mol. Neurosci. 2015, 56, 431-439. [CrossRef]

9. D'Amico, A.G.; Maugeri, G.; Reitano, R.; Bucolo, C.; Saccone, S.; Drago, F.; D'Agata, V. PACAP Modulates Expression of Hypoxia-Inducible Factors in Streptozotocin-Induced Diabetic Rat Retina. J. Mol. Neurosci. 2015, 57, 501-509. [CrossRef]

10. Yeung, Y.T.; McDonald, K.L.; Grewal, T.; Munoz, L. Interleukins in glioblastoma pathophysiology: Implications for therapy. Br. J. Pharm. 2013, 168, 591-606. [CrossRef] 
11. Zhang, W.; Petrovic, J.M.; Callaghan, D.; Jones, A.; Cui, H.; Howlett, C.; Stanimirovic, D. Evidence that hypoxia-inducible factor-1 (HIF-1) mediates transcriptional activation of interleukin-1beta (IL-1beta) in astrocyte cultures. J. Neuroimmunol. 2006, 174, 63-73. [CrossRef] [PubMed]

12. Shweiki, D.; Itin, A.; Soffer, D.; Keshet, E. Vascular endothelial growth factor induced by hypoxia may mediate hypoxia-initiated angiogenesis. Nature 1992, 359, 843-845. [CrossRef] [PubMed]

13. Fathima Hurmath, K.; Ramaswamy, P.; Nandakumar, D.N. IL-1 $\beta$ microenvironment promotes proliferation, migration, and invasion of human glioma cells. Cell Biol. Int. 2014, 38, 1415-1422. [CrossRef]

14. Ferrara, N. VEGF as a therapeutic target in cancer. Oncology 2005, 69, 11-16. [CrossRef] [PubMed]

15. Bracken, C.P.; Fedele, A.O.; Linke, S.; Balrak, W.; Lisy, K.; Whitelaw, M.L.; Peet, D.J. Cell-specific regulation of hypoxia-inducible factor (HIF)-1alpha and HIF-2alpha stabilization and transactivation in a graded oxygen environment. J. Biol. Chem. 2006, 281, 22575-22585. [CrossRef] [PubMed]

16. Kaur, B.; Khwaja, F.W.; Severson, E.A.; Matheny, S.L.; Brat, D.J.; Van Meir, E.G. Hypoxia and the hypoxia-inducible-factor pathway in glioma growth and angiogenesis. Neuro Oncol. 2005, 7, 134-153. [CrossRef]

17. Maugeri, G.; D’Amico, A.G.; Reitano, R.; Magro, G.; Cavallaro, S.; Salomone, S.; D'Agata, V. PACAP and VIP Inhibit the Invasiveness of Glioblastoma Cells Exposed to Hypoxia through the Regulation of HIFs and EGFR Expression. Front. Pharm. 2016, 7, 139. [CrossRef] [PubMed]

18. Tam, S.Y.; Wu, V.W.C.; Law, H.K.W. Hypoxia-Induced Epithelial-Mesenchymal Transition in Cancers: HIF-1 $\alpha$ and Beyond. Front. Oncol. 2020, 10, 486. [CrossRef]

19. Monteiro, A.R.; Hill, R.; Pilkington, G.J.; Madureira, P.A. The Role of Hypoxia in Glioblastoma Invasion. Cells 2017, 6, 45. [CrossRef]

20. Jing, Y.; Han, Z.; Zhang, S.; Liu, Y.; Wei, L. Epithelial-Mesenchymal Transition in tumor microenvironment. Cell Biosci. 2011, 1, 29. [CrossRef]

21. Ye, X.Z.; Xu, S.L.; Xin, Y.H.; Yu, S.C.; Ping, Y.F.; Chen, L.; Xiao, H.L.; Wang, B.; Yi, L.; Wang, Q.L.; et al. Tumor-associated microglia/macrophages enhance the invasion of glioma stem-like cells via TGF- $\beta 1$ signaling pathway. J. Immunol. 2012, 189, 444-453. [CrossRef]

22. Iwadate, Y. Epithelial-mesenchymal transition in glioblastoma progression. Oncol. Lett. 2016, 11, 1615-1620. [CrossRef] [PubMed]

23. Arimura, A. Perspectives on pituitary adenylate cyclase activating polypeptide (PACAP) in the neuroendocrine, endocrine, and nervous systems. Jpn. J. Physiol. 1998, 48, 301-331. [CrossRef]

24. Moody, T.W.; Nuche-Berenguer, B.; Jensen, R.T. Vasoactive intestinal peptide/pituitary adenylate cyclase activating polypeptide, and their receptors and cancer. Curr. Opin. Endocrinol. Diabetes Obes. 2016, 23, 38-47. [CrossRef] [PubMed]

25. D'Amico, A.G.; Maugeri, G.; Saccone, S.; Federico, C.; Cavallaro, S.; Reglodi, D.; D'Agata, V. PACAP Modulates the Autophagy Process in an In Vitro Model of Amyotrophic Lateral Sclerosis. Int. J. Mol. Sci. 2020, 21, 2943. [CrossRef] [PubMed]

26. Lauretta, G.; Ravalli, S.; Szychlinska, M.A.; Castorina, A.; Maugeri, G.; D'Amico, A.G.; D'Agata, V.; Musumeci, G. Current knowledge of pituitary adenylate cyclase activating polypeptide (PACAP) in articular cartilage. Histol. Histopathol. 2020, 16, 18233.

27. Cavallaro, S.; D'Agata, V.; Guardabasso, V.; Travali, S.; Stivala, F.; Canonico, P.L. Differentiation induces pituitary adenylate cyclase-activating polypeptide receptor expression in PC-12 cells. Mol. Pharm. 1995, 48, 56-62.

28. D'Agata, V.; Cavallaro, S.; Stivala, F.; Canonico, P.L. Tissue-specific and developmental expression of pituitary adenylate cyclase-activating polypeptide (PACAP) receptors in rat brain. Eur. J. Neurosci. 1996, 8, 310-318. [CrossRef]

29. Canonico, P.L.; Copani, A.; D'Agata, V.; Musco, S.; Petralia, S.; Travali, S.; Stivala, F.; Cavallaro, S. Activation of pituitary adenylate cyclase-activating polypeptide receptors prevents apoptotic cell death in cultured cerebellar granule cells. Ann. N. Y. Acad. Sci. 1996, 805, 470-472. [CrossRef] [PubMed]

30. Waschek, J.A. VIP and PACAP: Neuropeptide modulators of CNS inflammation, injury, and repair. Br. J. Pharm. 2013, 169, 512-523. [CrossRef]

31. Toth, D.; Szabo, E.; Tamas, A.; Juhasz, T.; Horvath, G.; Fabian, E.; Opper, B.; Szabo, D.; Maugeri, G.; D’Amico, A.G.; et al. Protective Effects of PACAP in Peripheral Organs. Front. Endocrinol. 2020, 11, 377. [CrossRef]

32. Reglodi, D.; Kiss, P.; Lubics, A.; Tamas, A. Review on the protective effects of PACAP in models of neurodegenerative diseases in vitro and in vivo. Curr. Pharm. Des. 2011, 17, 962-972. [CrossRef]

33. Maugeri, G.; D’Amico, A.G.; Gagliano, C.; Saccone, S.; Federico, C.; Cavallaro, S.; D'Agata, V. VIP Family Members Prevent Outer Blood Retinal Barrier Damage in a Model of Diabetic Macular Edema. J. Cell Physiol. 2017, 232, 1079-1085. [CrossRef] [PubMed]

34. Maugeri, G.; D'Amico, A.G.; Saccone, S.; Federico, C.; Cavallaro, S.; D'Agata, V. PACAP and VIP Inhibit HIF-1 $\alpha$-Mediated VEGF Expression in a Model of Diabetic Macular Edema. J. Cell Physiol. 2017, 232, 1209-1215. [CrossRef]

35. Maugeri, G.; D'Amico, A.G.; Bucolo, C.; D'Agata, V. Protective effect of PACAP-38 on retinal pigmented epithelium in an in vitro and in vivo model of diabetic retinopathy through EGFR-dependent mechanism. Peptides 2019, 119, 170108. [CrossRef]

36. Maugeri, G.; D'Amico, A.G.; Castrogiovanni, P.; Saccone, S.; Federico, C.; Reibaldi, M.; Russo, A.; Bonfiglio, V.; Avitabile, T.; Longo, A.; et al. PACAP through EGFR transactivation preserves human corneal endothelial integrity. J. Cell Biochem. 2019, 120, 10097-10105. [CrossRef] 
37. Maugeri, G.; D’Amico, A.G.; Rasà, D.M.; Federico, C.; Saccone, S.; Morello, G.; La Cognata, V.; Cavallaro, S.; D'Agata, V. Molecular mechanisms involved in the protective effect of pituitary adenylate cyclase-activating polypeptide in an in vitro model of amyotrophic lateral sclerosis. J. Cell Physiol. 2019, 234, 5203-5214. [CrossRef] [PubMed]

38. Maugeri, G.; D’Amico, A.G.; Musumeci, G.; Reglodi, D.; D’Agata, V. Effects of Pacap on Schwann Cells: Focus on Nerve Injury. Int. J. Mol. Sci. 2020, 21, 8233. [CrossRef] [PubMed]

39. Maugeri, G.; D'Amico, A.G.; Morello, G.; Reglodi, D.; Cavallaro, S.; D'Agata, V. Differential Vulnerability of Oculomotor Versus Hypoglossal Nucleus During ALS: Involvement of PACAP. Front. Neurosci. 2020, 14, 805. [CrossRef] [PubMed]

40. Maugeri, G.; D’Amico, A.G.; Rasà, D.M.; Saccone, S.; Federico, C.; Cavallaro, S.; D'Agata, V. PACAP and VIP regulate hypoxiainducible factors in neuroblastoma cells exposed to hypoxia. Neuropeptides 2018, 69, 84-91. [CrossRef]

41. Castorina, A.; Scuderi, S.; D'Amico, A.G.; Drago, F.; D'Agata, V. PACAP and VIP increase the expression of myelin-related proteins in rat schwannoma cells: Involvement of PAC1/VPAC2 receptor-mediated activation of PI3K/Akt signaling pathways. Exp. Cell Res. 2014, 322, 108-121. [CrossRef] [PubMed]

42. Castorina, A.; Giunta, S.; Scuderi, S.; D'Agata, V. Involvement of PACAP/ADNP signaling in the resistance to cell death in malignant peripheral nerve sheath tumor (MPNST) cells. J. Mol. Neurosci. 2012, 48, 674-683. [CrossRef] [PubMed]

43. D'Amico, A.G.; Scuderi, S.; Saccone, S.; Castorina, A.; Drago, F.; D'Agata, V. Antiproliferative effects of PACAP and VIP in serum-starved glioma cells. J. Mol. Neurosci. 2013, 51, 503-513. [CrossRef] [PubMed]

44. Vertongen, P.; d'Haens, J.; Michotte, A.; Velkeniers, B.; van Rampelbergh, J.; Svoboda, M.; Robberecht, P. Expression of pituitary adenylate cyclase activating polypeptide and receptors in human brain tumors. Peptides 1995, 16, 713-719. [CrossRef]

45. Jaworski, D.M. Expression of pituitary adenylate cyclase-activating polypeptide (PACAP) and the PACAP-selective receptor in cultured rat astrocytes, human brain tumors, and in response to acute intracranial injury. Cell Tissue Res. 2000, 300, 219-230. [CrossRef] [PubMed]

46. Robberecht, P.; Woussen-Colle, M.C.; Vertongen, P.; De Neef, P.; Hou, X.; Salmon, I.; Brotchi, J. Expression of pituitary adenylate cyclase activating polypeptide (PACAP) receptors in human glial cell tumors. Peptides 1994, 15, 661-665. [CrossRef]

47. Reubi, J.C.; Läderach, U.; Waser, B.; Gebbers, J.O.; Robberecht, P.; Laissue, J.A. Vasoactive intestinal peptide/pituitary adenylate cyclase-activating peptide receptor subtypes in human tumors and their tissues of origin. Cancer Res. 2000, 60, 3105-3112 [PubMed]

48. Sharma, A.; Walters, J.; Gozes, Y.; Fridkin, M.; Brenneman, D.; Gozes, I.; Moody, T.W. A vasoactive intestinal peptide antagonist inhibits the growth of glioblastoma cells. J. Mol. Neurosci. 2001, 17, 331-339. [CrossRef]

49. Available online: https:/ / www.proteinatlas.org/ENSG00000141433-ADCYAP1/pathology/glioma (accessed on 12 July 2021).

50. Sokolowska, P.; Nowak, J.Z. Effects of PACAP and VIP on cAMP-generating system and proliferation of C6 glioma cells. J. Mol. Neurosci. 2008, 36, 286-291. [CrossRef]

51. Dufes, C.; Alleaume, C.; Montoni, A.; Olivier, J.C.; Muller, J.M. Effects of the vasoactive intestinal peptide (VIP) and related peptides on glioblastoma cell growth in vitro. J. Mol. Neurosci. 2003, 21, 91-102. [CrossRef]

52. Vertongen, P.; Camby, I.; Darro, F.; Kiss, R.; Robberecht, P. VIP and pituitary adenylate cyclase activating polypeptide (PACAP) have an antiproliferative effect on the T98G human glioblastoma cell line through interaction with VIP2 receptor. Neuropeptides 1996, 30, 491-496. [CrossRef]

53. Cochaud, S.; Chevrier, L.; Meunier, A.C.; Brillet, T.; Chadéneau, C.; Muller, J.M. The vasoactive intestinal peptide-receptor system is involved in human glioblastoma cell migration. Neuropeptides 2010, 44, 373-383. [CrossRef]

54. Cochaud, S.; Meunier, A.C.; Monvoisin, A.; Bensalma, S.; Muller, J.M.; Chadéneau, C. Neuropeptides of the VIP family inhibit glioblastoma cell invasion. J. Neurooncol. 2015, 122, 63-73. [CrossRef]

55. Kubiatowski, T.; Jang, T.; Lachyankar, M.B.; Salmonsen, R.; Nabi, R.R.; Quesenberry, P.J.; Litofsky, N.S.; Ross, A.H.; Recht, L.D Association of increased phosphatidylinositol 3-kinase signaling with increased invasiveness and gelatinase activity in malignant gliomas. J. Neurosurg. 2001, 95, 480-488. [CrossRef] [PubMed]

56. Bensalma, S.; Turpault, S.; Balandre, A.C.; De Boisvilliers, M.; Gaillard, A.; Chadéneau, C.; Muller, J.M. PKA at a Cross-Road of Signaling Pathways Involved in the Regulation of Glioblastoma Migration and Invasion by the Neuropeptides VIP and PACAP. Cancers 2019, 11, 123. [CrossRef] [PubMed]

57. Paw, I.; Carpenter, R.C.; Watabe, K.; Debinski, W.; Lo, H.W. Mechanisms regulating glioma invasion. Cancer Lett. 2015, $362,1-7$. [CrossRef] [PubMed]

58. Li, M.; Hering-Smith, K.S.; Simon, E.E.; Batuman, V. Myeloma light chains induce epithelial-mesenchymal transition in human renal proximal tubule epithelial cells. Nephrol. Dial. Transplant. 2008, 23, 860-870. [CrossRef]

59. Maugeri, G.; D’Amico, A.G.; Rasà, D.M.; Saccone, S.; Federico, C.; Magro, G.; Cavallaro, S.; D'Agata, V. Caffeine effect on HIFs/VEGF pathway in human glioblastoma cells exposed to hypoxia. Anticancer Agents Med. Chem. 2018, 18, 1432-1439. [CrossRef]

60. Maugeri, G.; Longo, A.; D’Amico, A.G.; Rasà, D.M.; Reibaldi, M.; Russo, A.; Bonfiglio, V.; Avitabile, T.; D'Agata, V. Trophic effect of PACAP on human corneal endothelium. Peptides 2018, 99, 20-26. [CrossRef]

61. D'Amico, A.G.; Scuderi, S.; Maugeri, G.; Cavallaro, S.; Drago, F.; D’Agata, V. NAP reduces murine microvascular endothelial cells proliferation induced by hyperglycemia. J. Mol. Neurosci. 2014, 54, 405-413. [CrossRef] 
62. Maugeri, G.; D’Amico, A.G.; Rasà, D.M.; La Cognata, V.; Saccone, S.; Federico, C.; Cavallaro, S.; D'Agata, V. Nicotine promotes blood retinal barrier damage in a model of human diabetic macular edema. Toxicol. In Vitro 2017, 44, 182-189. [CrossRef] [PubMed]

63. D'Amico, A.G.; Maugeri, G.; Bucolo, C.; Saccone, S.; Federico, C.; Cavallaro, S.; D'Agata, V. Nap Interferes with Hypoxia-Inducible Factors and VEGF Expression in Retina of Diabetic Rats. J. Mol. Neurosci. 2017, 61, 256-266. [CrossRef]

64. Maugeri, G.; D'Amico, A.G.; Rasà, D.M.; Reitano, R.; Saccone, S.; Federico, C.; Parenti, R.; Magro, G.; D'Agata, V. Expression profile of Wilms Tumor 1 (WT1) isoforms in undifferentiated and all-trans retinoic acid differentiated neuroblastoma cells. Genes Cancer 2016, 7, 47-58. [CrossRef]

65. Danielsson, F.; Peterson, M.K.; Caldeira Araújo, H.; Lautenschläger, F.; Gad, A.K.B. Vimentin Diversity in Health and Disease. Cells 2018, 7, 147. [CrossRef] [PubMed]

66. McNeil, E.; Capaldo, C.T.; Macara, I.G. Zonula Occludens-1 Function in the Assembly of Tight Junctions in Madin-Darby Canine Kidney Epithelial Cells. Mol. Biol. Cell 2006, 17, 1922-1932. [CrossRef]

67. Toole, B.P. Hyaluronan-CD44 interactions in cancer: Paradoxes and possibilities. Clin. Cancer Res. 2009, 15, 7462-7468. [CrossRef] [PubMed]

68. Wolf, K.J.; Shukla, P.; Springer, K.; Lee, S.; Coombes, J.D.; Choy, C.J.; Kenny, S.J.; Xu, K.; Kumar, S. A mode of cell adhesion and migration facilitated by CD44-dependent microtentacles. Proc. Natl. Acad. Sci. USA 2020, 117, 11432-11443. [CrossRef]

69. Yu, R.; Zhong, J.; Li, M.; Guo, X.; Zhang, H.; Chen, J. PACAP induces the dimerization of PAC1 on the nucleus associated with the cAMP increase in the nucleus. Neurosci. Lett. 2013, 549, 92-96. [CrossRef] [PubMed]

70. Yu, R.; Lin, Z.; Ouyang, Z.; Tao, Z.; Fan, G. Blue light induces the nuclear translocation of neuropeptide receptor PAC1-R associated with the up-regulation of PAC1-R its own in reactive oxygen species associated way. Biochim. Biophys. Acta Gen. Subj. 2021, 1865, 129884. [CrossRef]

71. Mottet, D.; Michel, G.; Renard, P.; Ninane, N.; Raes, M.; Michiels, C. ERK and calcium in activation of HIF-1. Ann. N. Y. Acad. Sci. 2002, 973, 448-453. [CrossRef]

72. Lim, J.H.; Lee, E.S.; You, H.J.; Lee, J.W.; Park, J.W.; Chun, Y.S. Ras-dependent induction of HIF-1alpha785 via the Raf/MEK/ERK pathway: A novel mechanism of Ras-mediated tumor promotion. Oncogene 2004, 23, 9427-9431. [CrossRef]

73. Park, J.H.; Lee, J.Y.; Shin, D.H.; Jang, K.S.; Kim, H.J.; Kong, G. Loss of Mel-18 induces tumor angiogenesis through enhancing the activity and expression of HIF-1alpha mediated by the PTEN/PI3K/Akt pathway. Oncogene 2011, 10, 4578-4589. [CrossRef] [PubMed]

74. Sharma, V.; Dixit, D.; Koul, N.; Mehta, V.S.; Sen, E. Ras regulates interleukin-1 $\beta$-induced HIF- $1 \alpha$ transcriptional activity in glioblastoma. J. Mol. Med. 2011, 89, 123-136. [CrossRef] [PubMed]

75. Bergers, G.; Benjamin, L.E. Tumorigenesis and the angiogenic switch. Nat. Rev. Cancer 2003, 3, 401-410. [CrossRef] [PubMed]

76. Plate, K.H.; Breier, G.; Weich, H.A.; Risau, W. Vascular endothelial growth factor is a potential tumour angiogenesis factor in human gliomas in vivo. Nature 1992, 359, 845-848. [CrossRef]

77. Moreno, M.J.; Ball, M.; Andrade, M.F.; McDermid, A.; Stanimirovic, D.B. Insulin-like growth factor binding protein-4 (IGFBP-4) is a novel anti-angiogenic and anti-tumorigenic mediator secreted by dibutyryl cyclic AMP (dB-cAMP)-differentiated glioblastoma cells. Glia 2006, 53, 845-857. [CrossRef] [PubMed]

78. Pen, A.; Moreno, M.J.; Durocher, Y.; Deb-Rinker, P.; Stanimirovic, D.B. Glioblastoma-secreted factors induce IGFBP7 and angiogenesis by modulating Smad-2-dependent TGF-beta signaling. Oncogene 2008, 27, 6834-6844. [CrossRef]

79. Papale, M.; Buccarelli, M.; Mollinari, C.; Russo, M.A.; Pallini, R.; Ricci-Vitiani, L.; Tafani, M. Hypoxia, Inflammation and Necrosis as Determinants of Glioblastoma Cancer Stem Cells Progression. Int. J. Mol. Sci. 2020, 21, 2660. [CrossRef]

80. Joseph, J.V.; Conroy, S.; Pavlov, K.; Sontakke, P.; Tomar, T.; Eggens-Meijer, E.; Balasubramaniyan, V.; Wagemakers, M.; den Dunnen, W.F.; Kruyt, F.A. Hypoxia enhances migration and invasion in glioblastoma by promoting a mesenchymal shift mediated by the HIF1 $\alpha$-ZEB1 axis. Cancer Lett. 2015, 359, 107-116. [CrossRef]

81. Roomi, M.W.; Kalinovsky, T.; Rath, M.; Niedzwiecki, A. Modulation of MMP-2 and MMP-9 secretion by cytokines, inducers and inhibitors in human glioblastoma T-98G cells. Oncol. Rep. 2017, 37, 1907-1913. [CrossRef]

82. Marhaba, R.; Zöller, M. CD44 in cancer progression: Adhesion, migration and growth regulation. J. Mol. Histol. 2004, 35, $211-231$. [CrossRef] [PubMed]

83. Fakhri, S.; Mehrjardi, A.Z.; Noori, M. Expression of CD44 and CD133 in glioma stem cells. Int. J. Tumor Ther. 2018, 7, 27-33.

84. Kinashi, Y.; Ikawa, T.; Takahashi, S. The combined effect of neutron irradiation and temozolomide on glioblastoma cell lines with different MGMT and P53 status. Appl. Radiat. Isot. 2020, 163, 109204. [CrossRef] [PubMed] 